\title{
Spatial patterns of summer speedup on south-central Alaska Glaciers revealed from repeat satellite imagery
}

William Armstrong ${ }^{1,2,3}$, Robert Anderson ${ }^{2,3}$, Mark Fahnestock ${ }^{4}$ ${ }^{1}$ Deoartment of Geological and Environmental Sciences, Appalachian State University, Boone, NC, USA ${ }^{2}$ Institute of Arctic and Alpine Research, University of Colorado at Boulder, CO USA ${ }^{3}$ Department of Geological Sciences, University of Colorado at Boulder, CO USA ${ }^{4}$ Geophysical Institute, University of Alaska Fairbanks, AK USA
APPALACHIAN GEOLOGICAL AND ENVIRONMENTAL SCIENCES

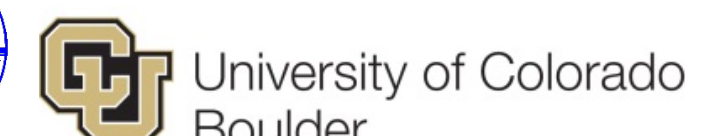
University of Colorado
Boulder 


\section{Motivation}

Glacier dynamics

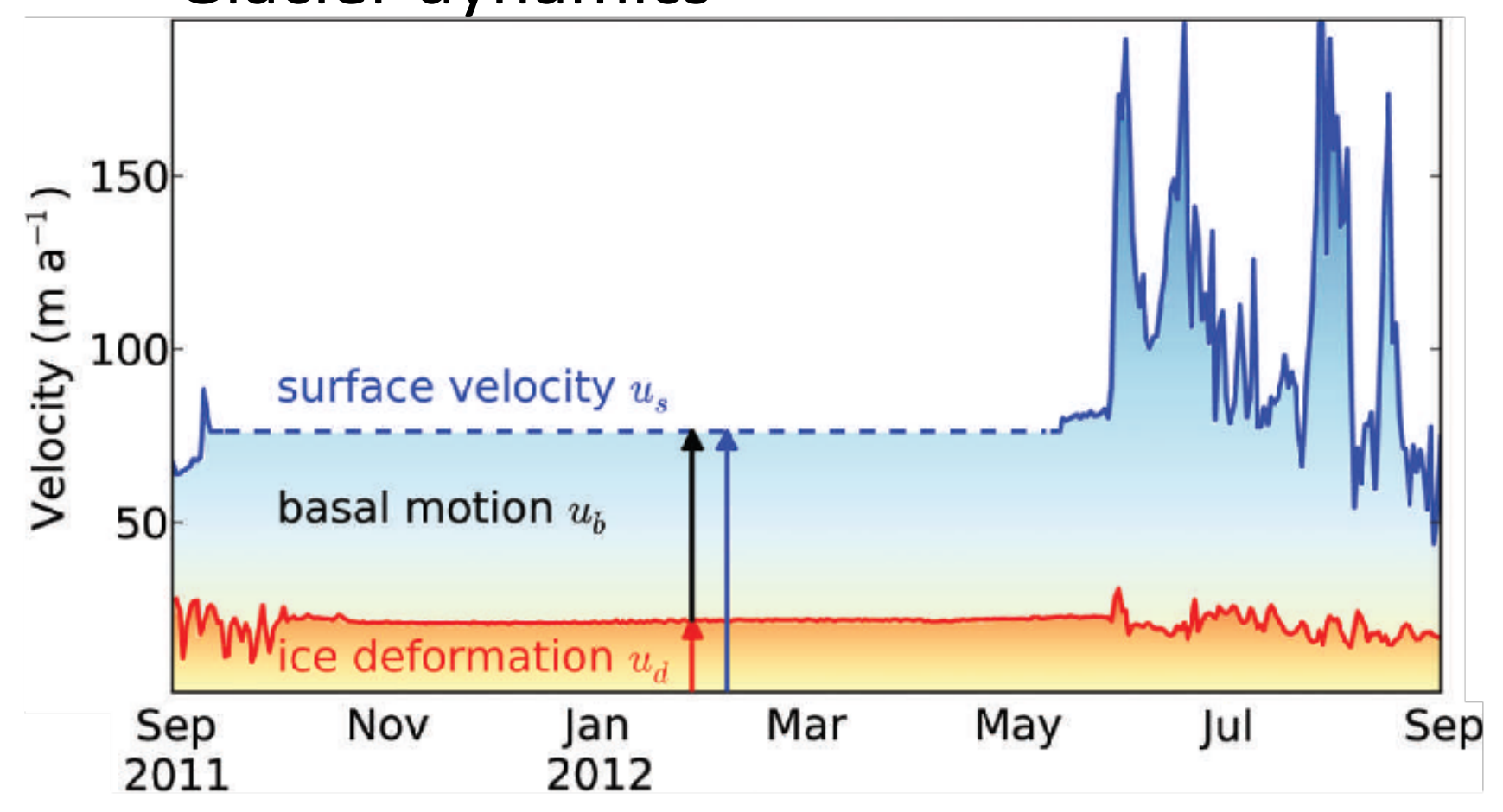

\section{Glacier erosion}

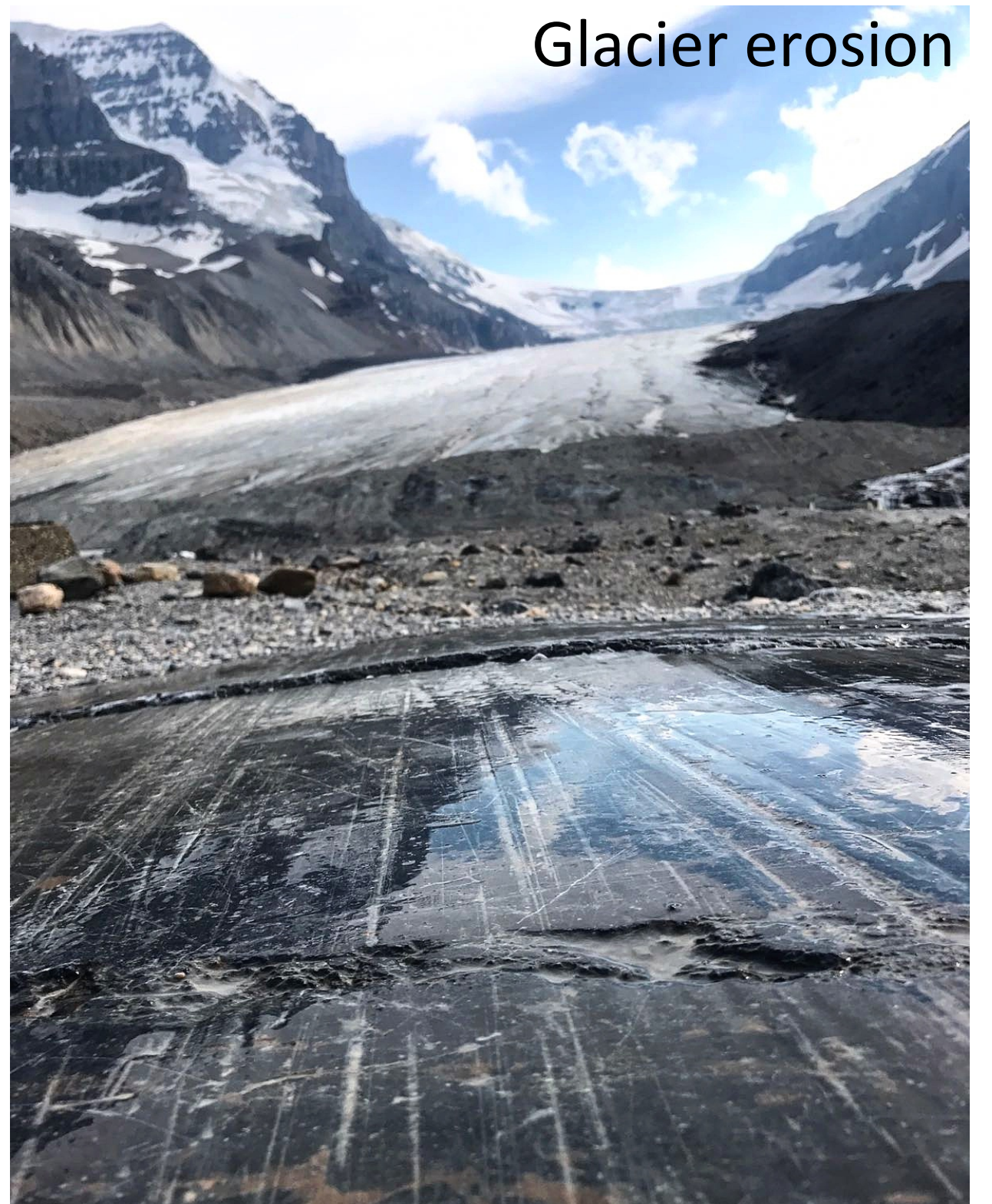




\section{Motivation}
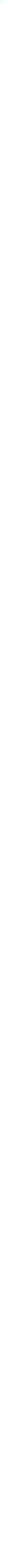

Figure: Mike Willis; Photo: Sarah Evans 


\section{Motivation}

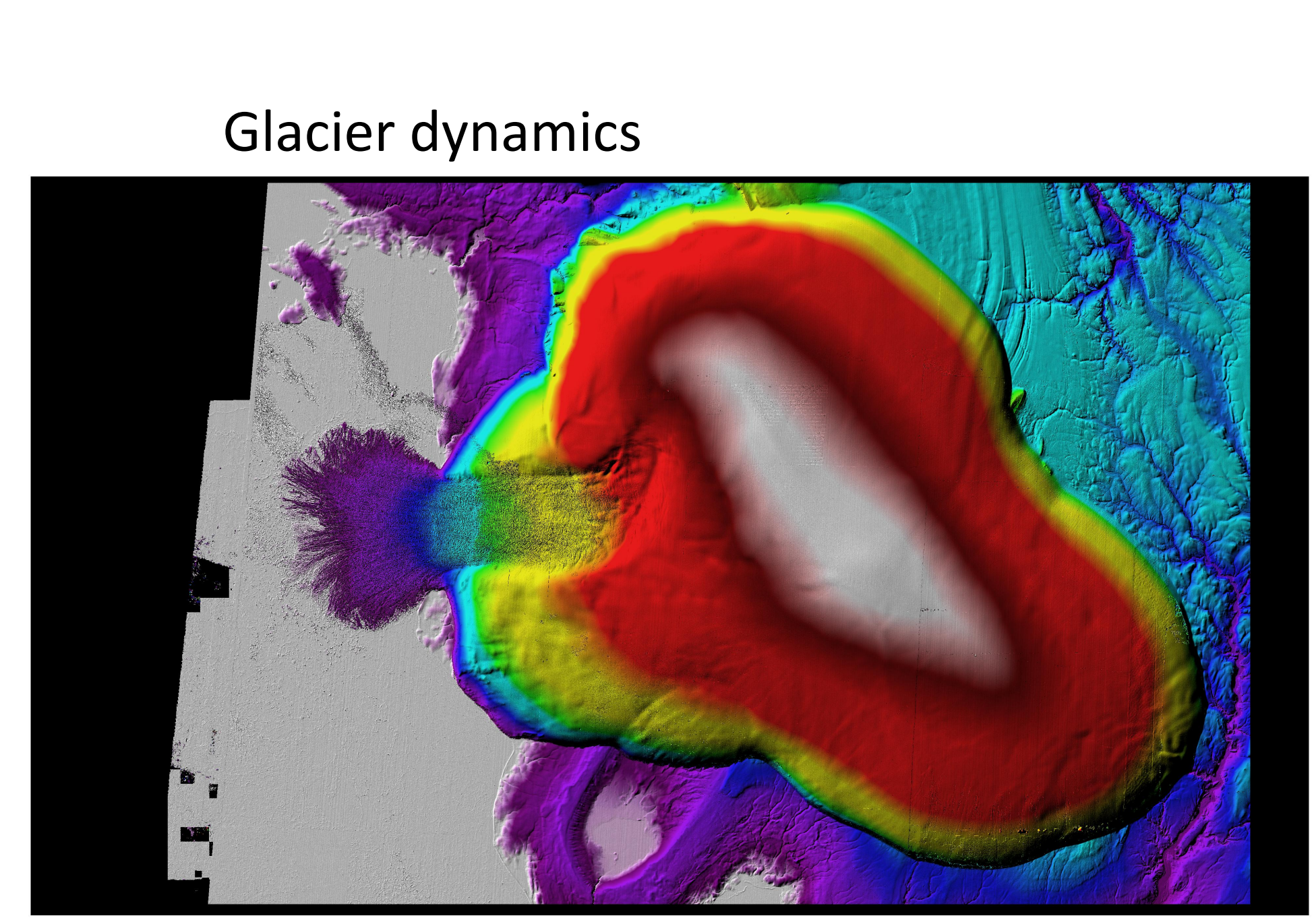

Figure: Mike Willis; Photo: Sarah Evans

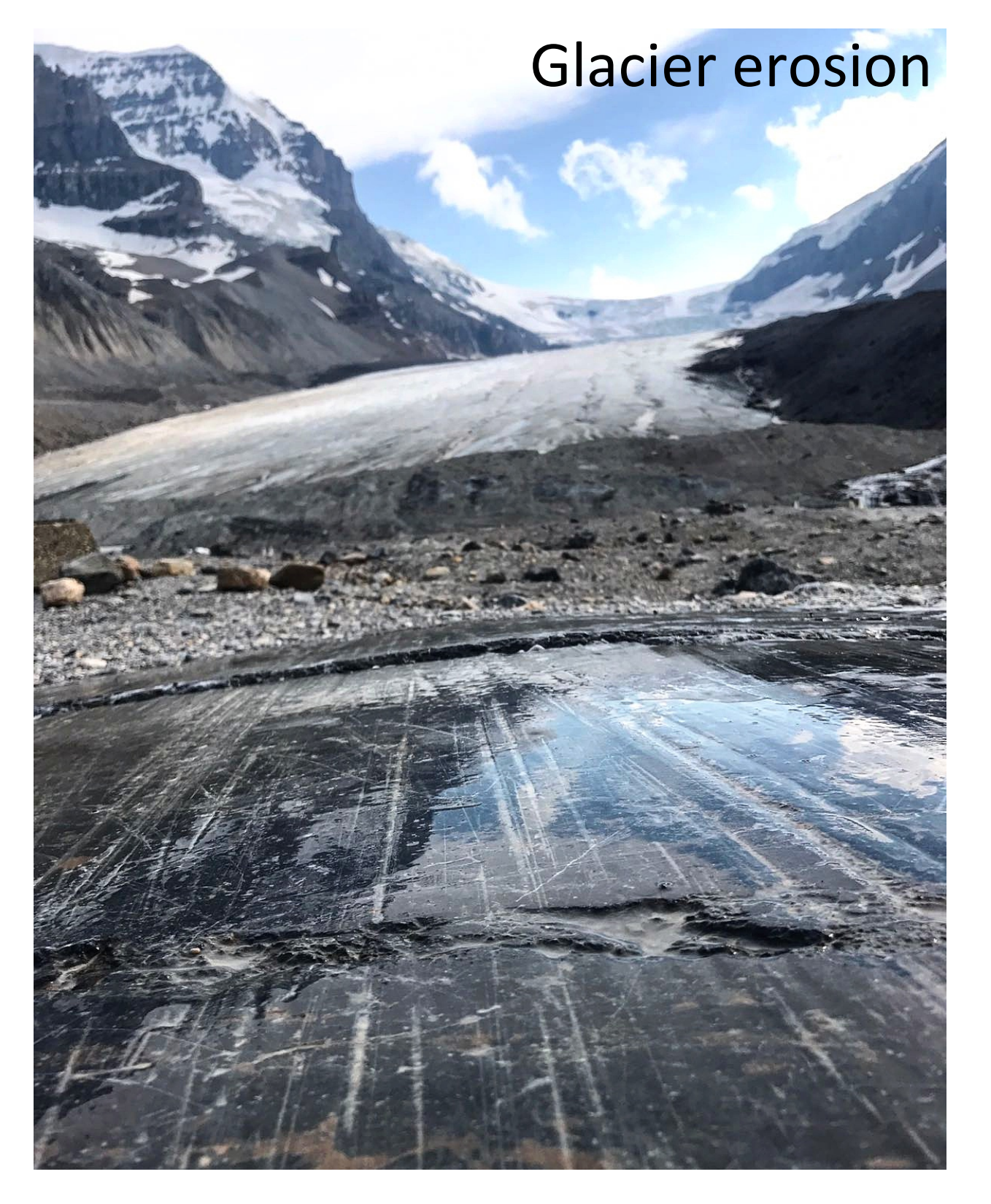

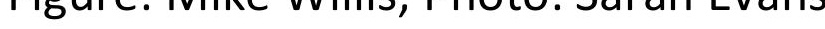




\section{Research questions}

- Are there consistent

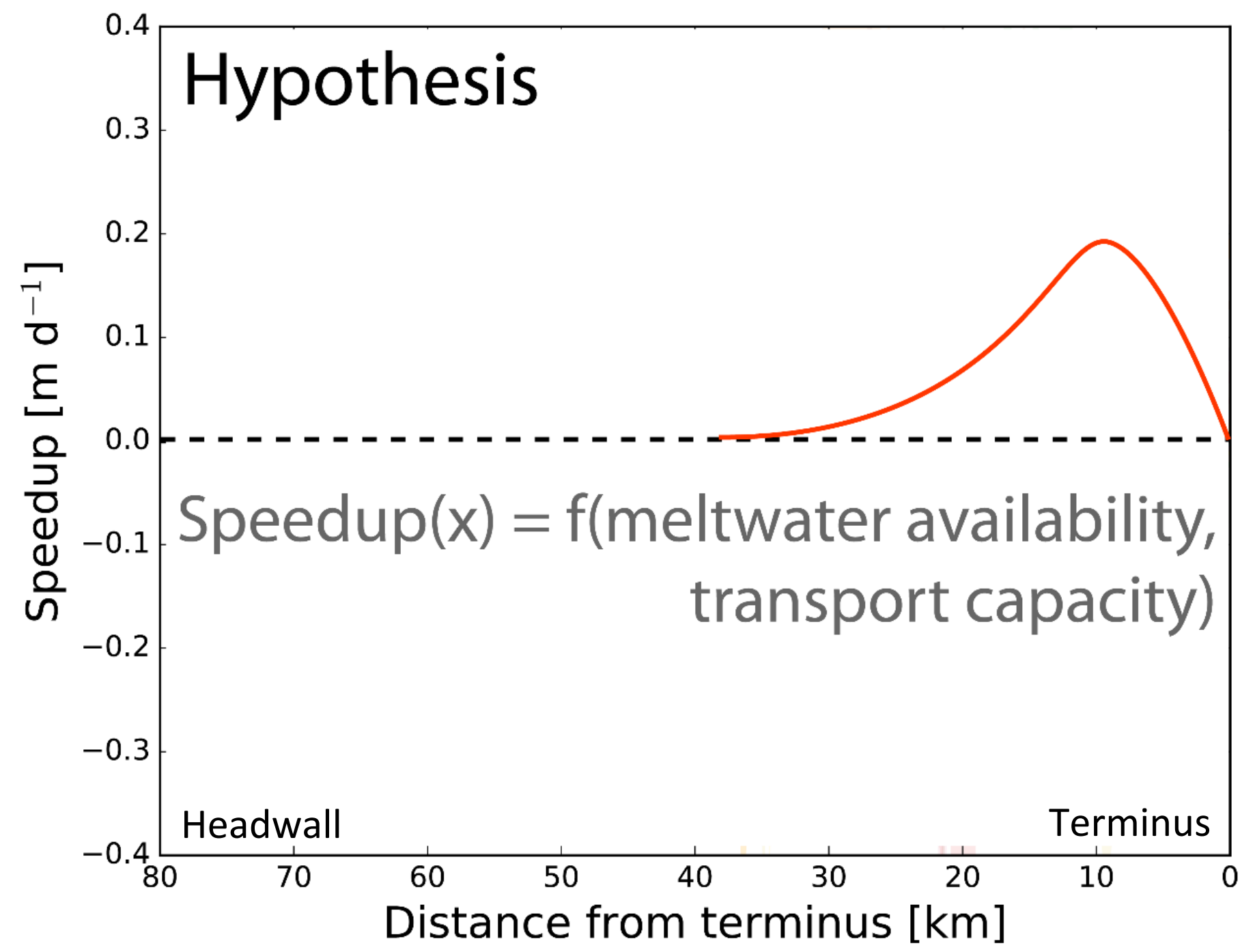

- Seasonal velocity fluctuations over large scale patterns of basal motion?

-What controls these patterns? 


\section{Study area}

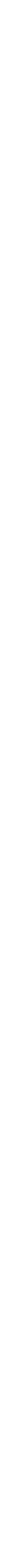




\section{Study area}

- 43 glaciers

- 64 centerline profiles

-Wrangells, St Elias

- Largely land-terminating

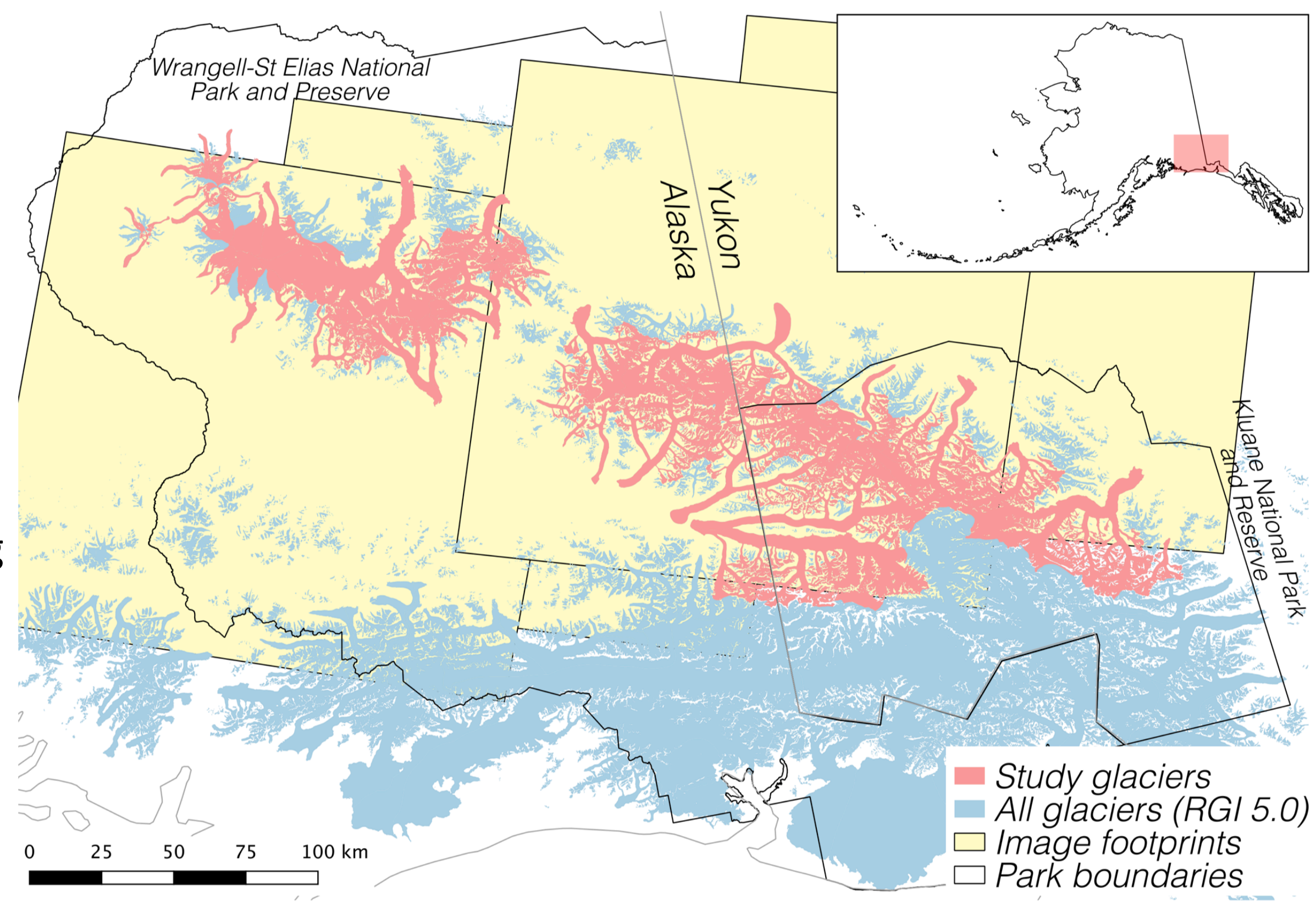




\section{Image cross-correlation}

- PyCorr software

- Fahnestock et al., [2016]; Remote Sensing of Environment

Time 1

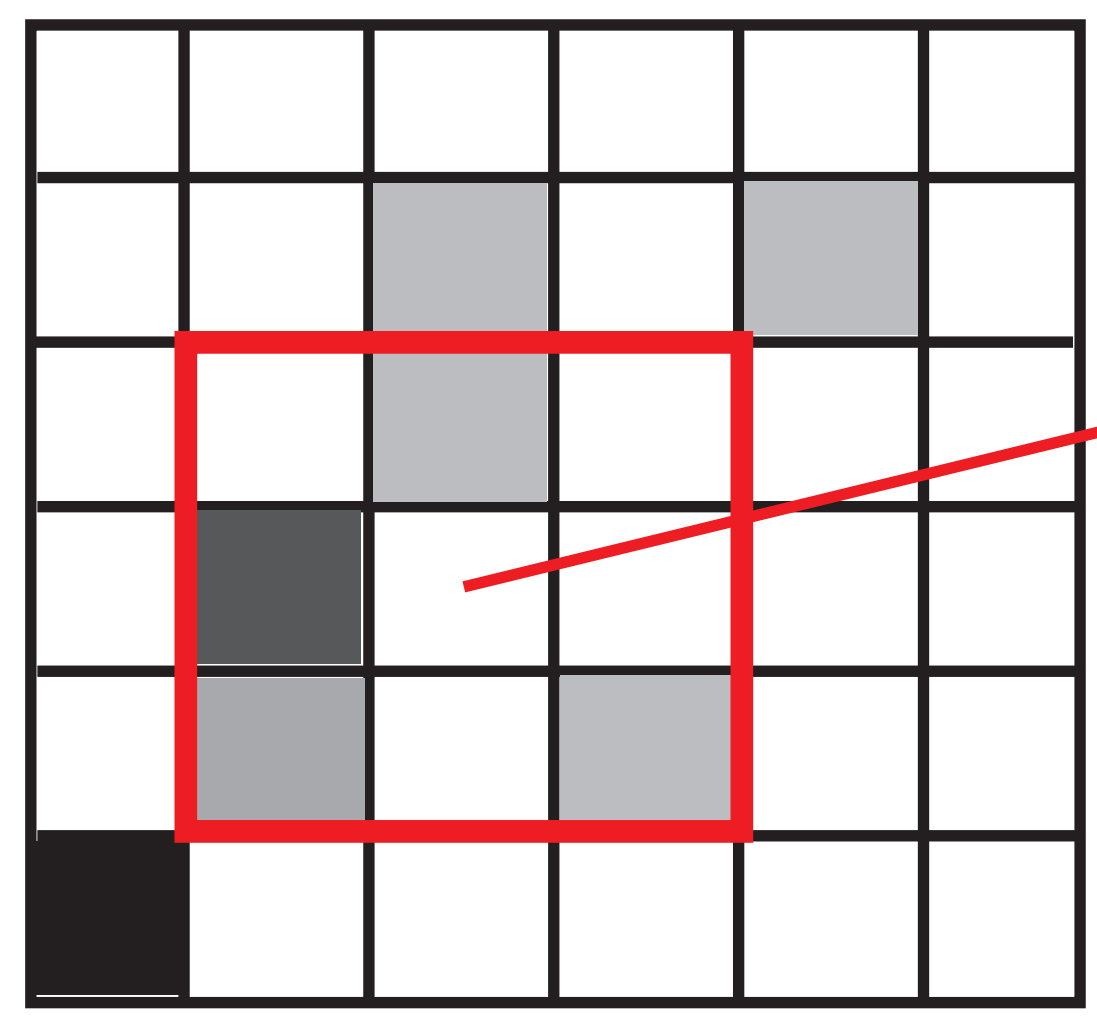

Time 2

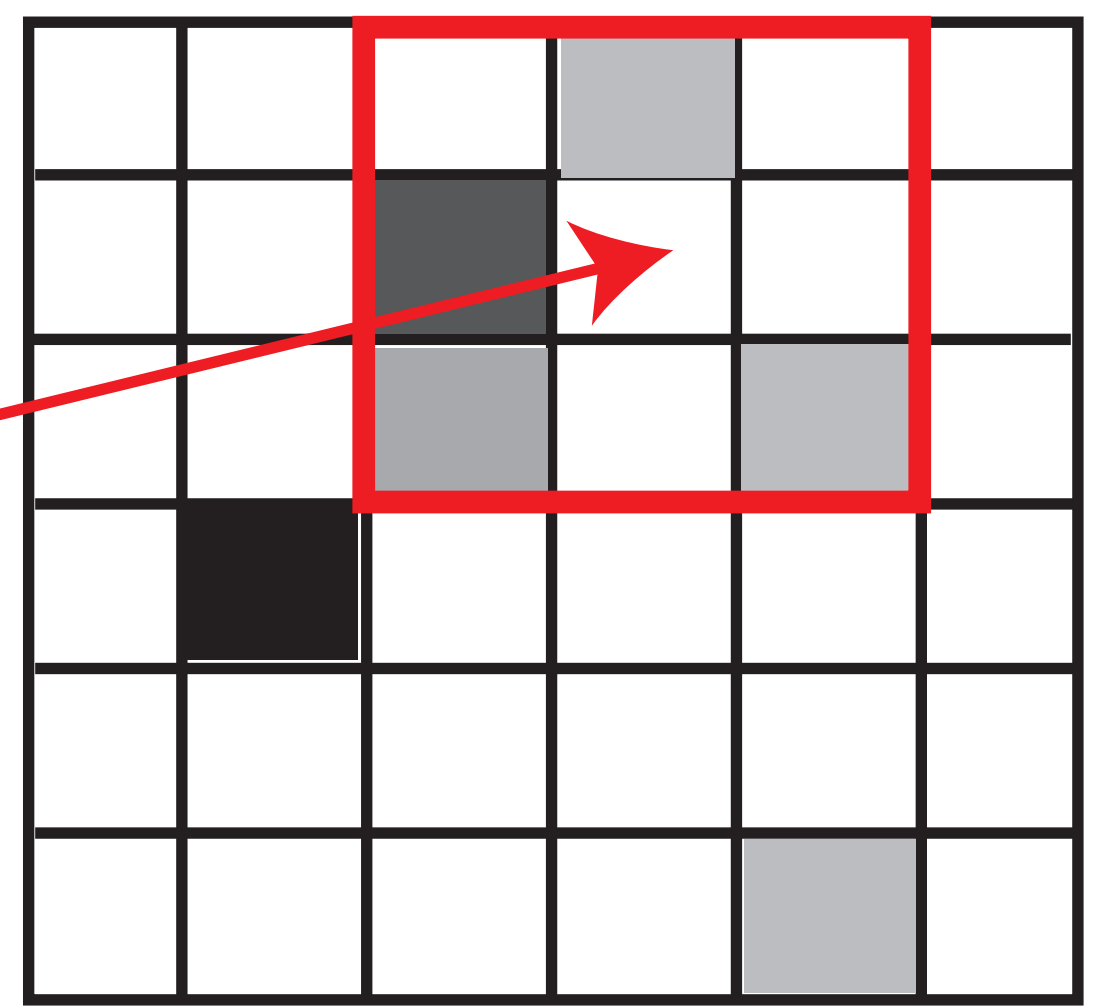




\section{Image cross-correlation}

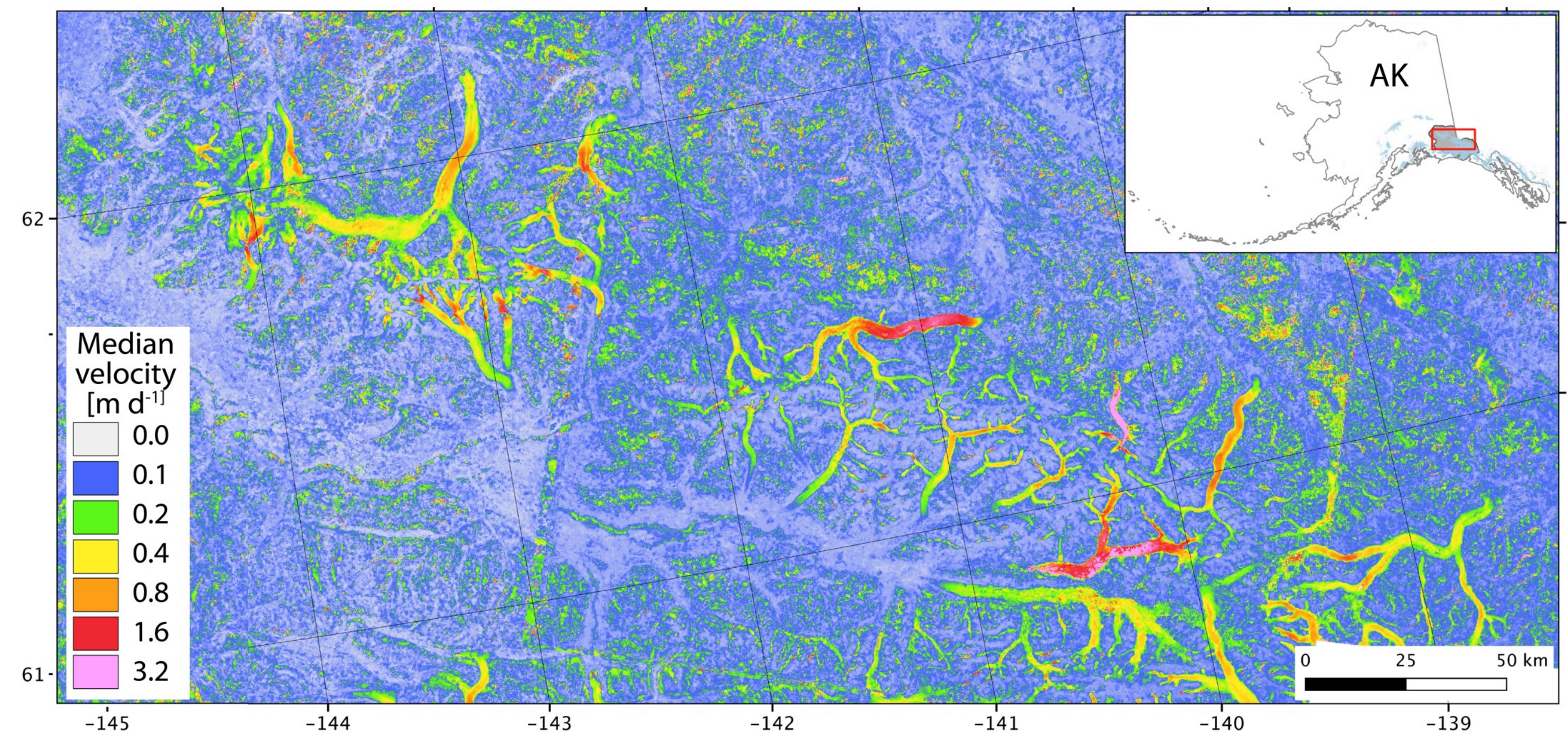

Armstrong et al. [2017], Geophys. Res. Lett. 


\section{Image cross-correlation}

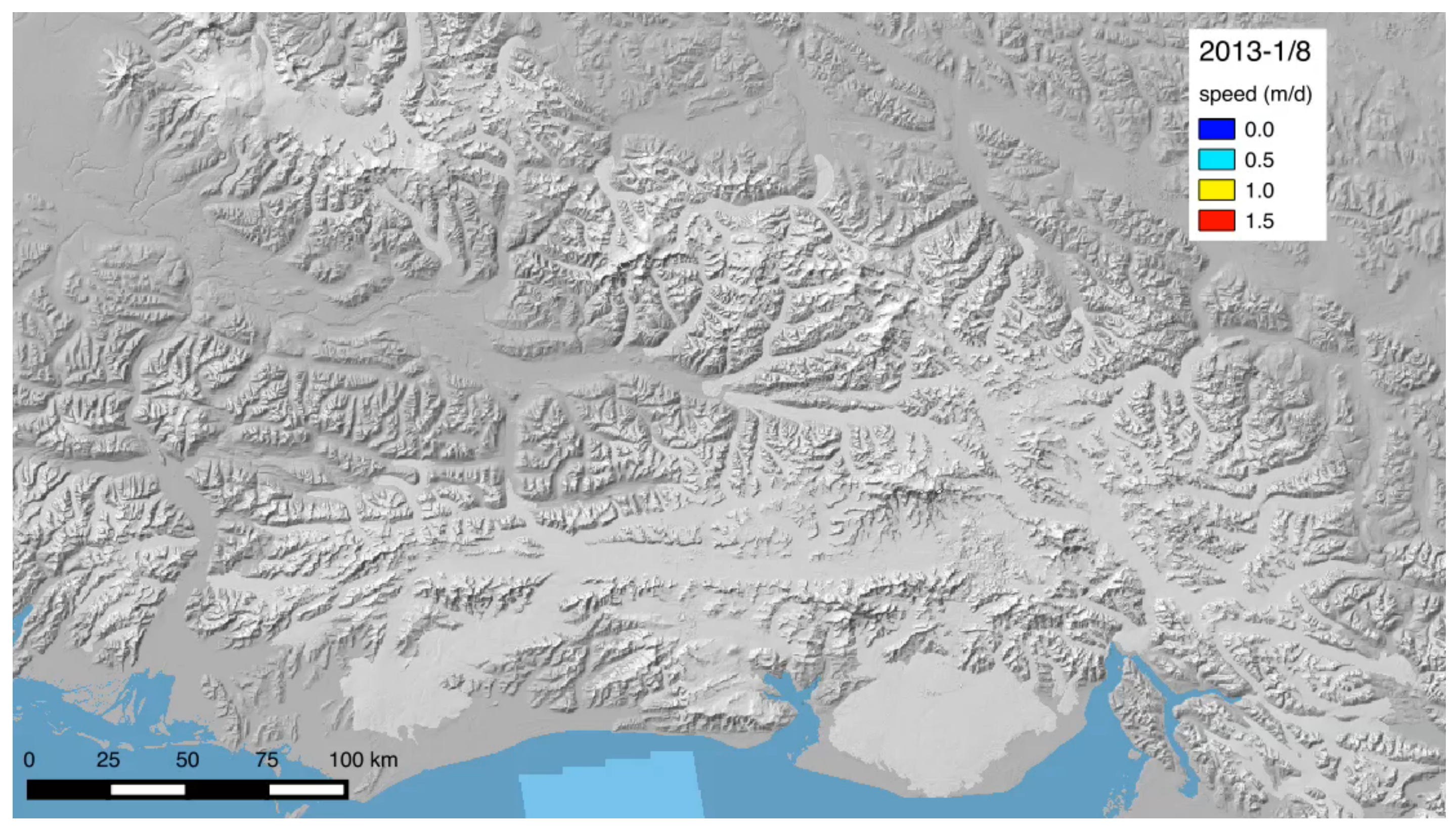




\section{Swath profiling}

- Reduce noise by averaging over area

- $\mathrm{W} \times \mathrm{L}=500 \times 1000 \mathrm{~m}$

- $\sigma$ and $n$ as quality filters

- Additional filtering from correlation results

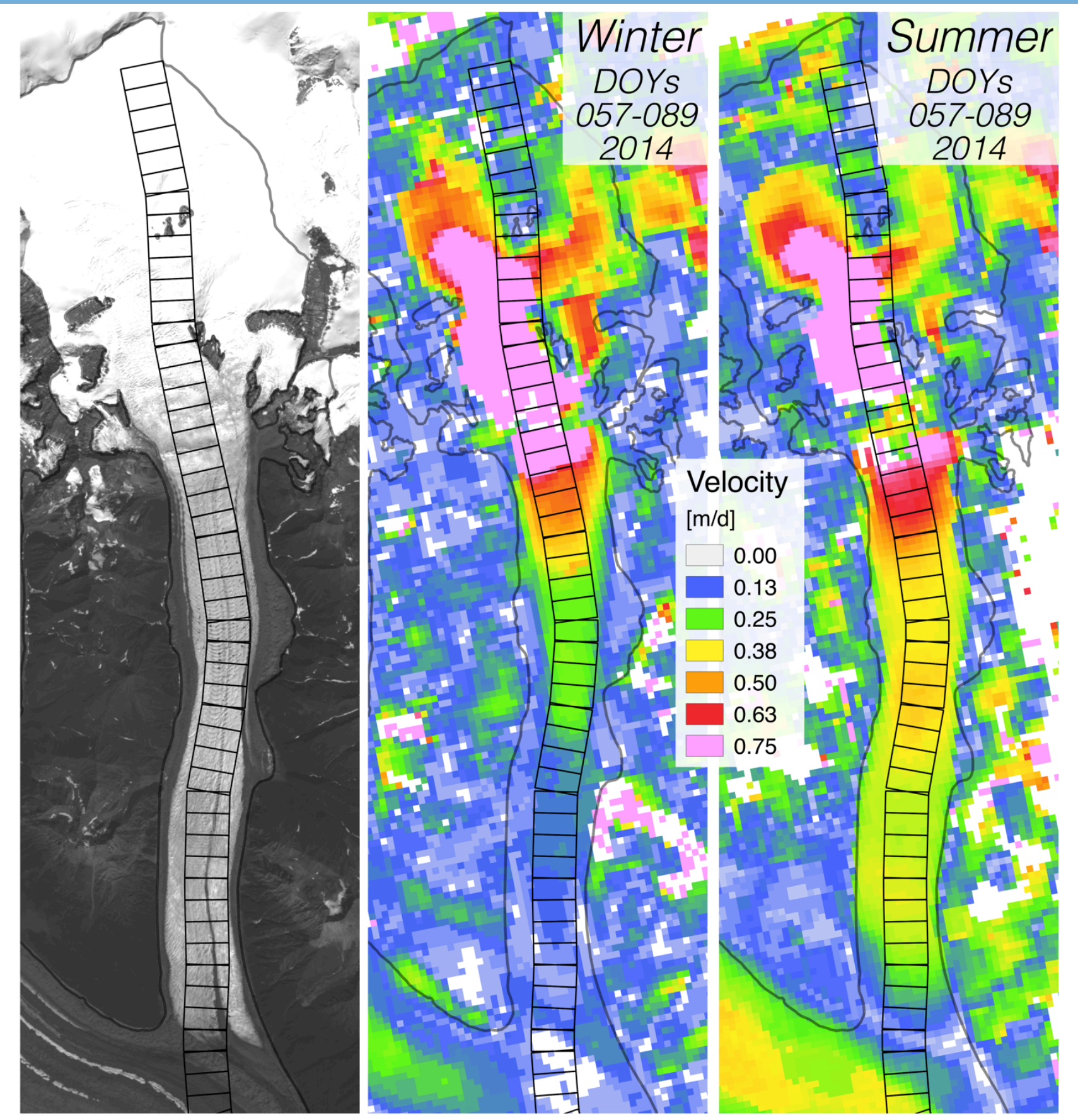




\section{Speedup profiles}
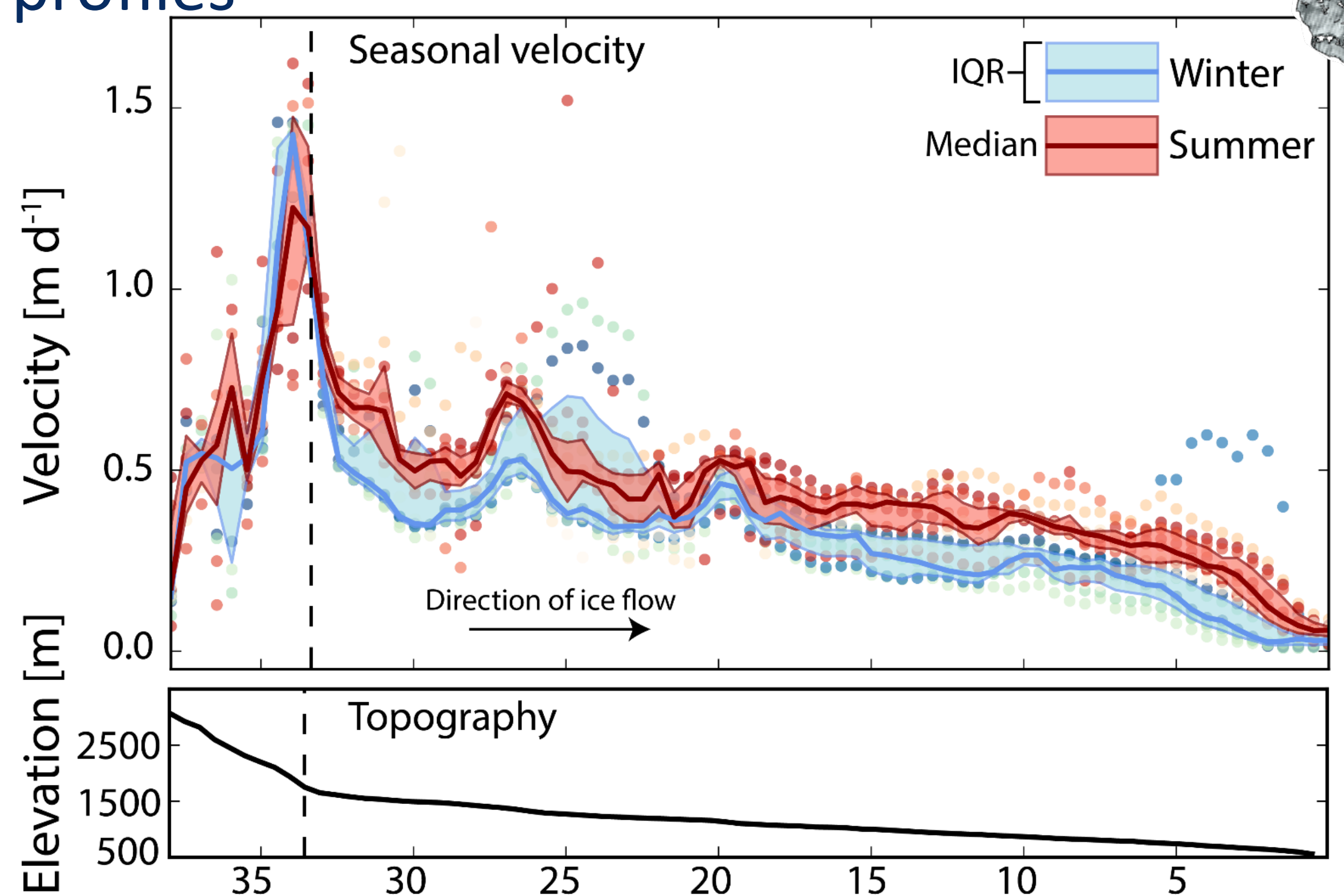


\section{Speedup profiles}
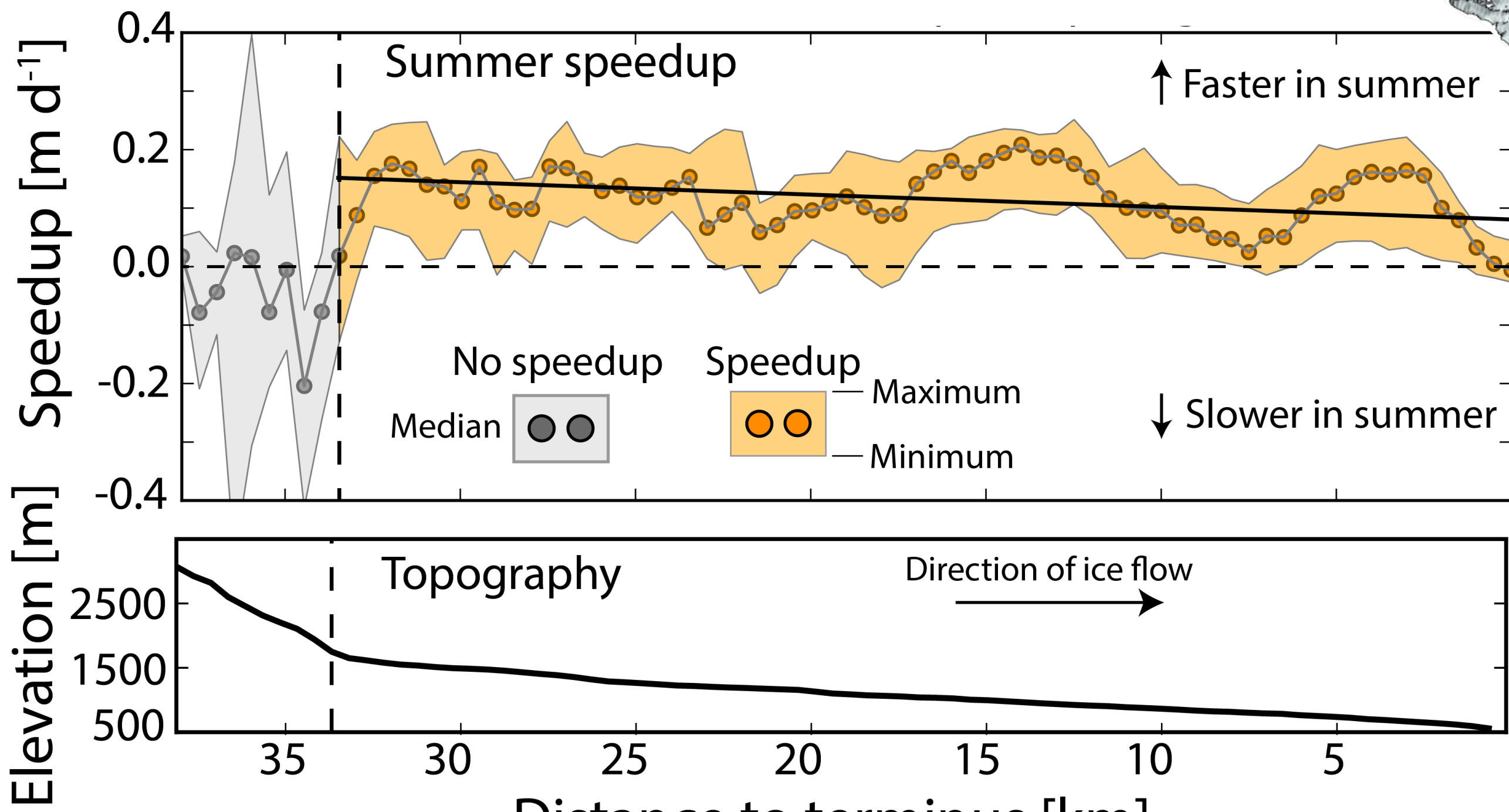

Distance to terminus [km] 


\section{Speedup profiles}

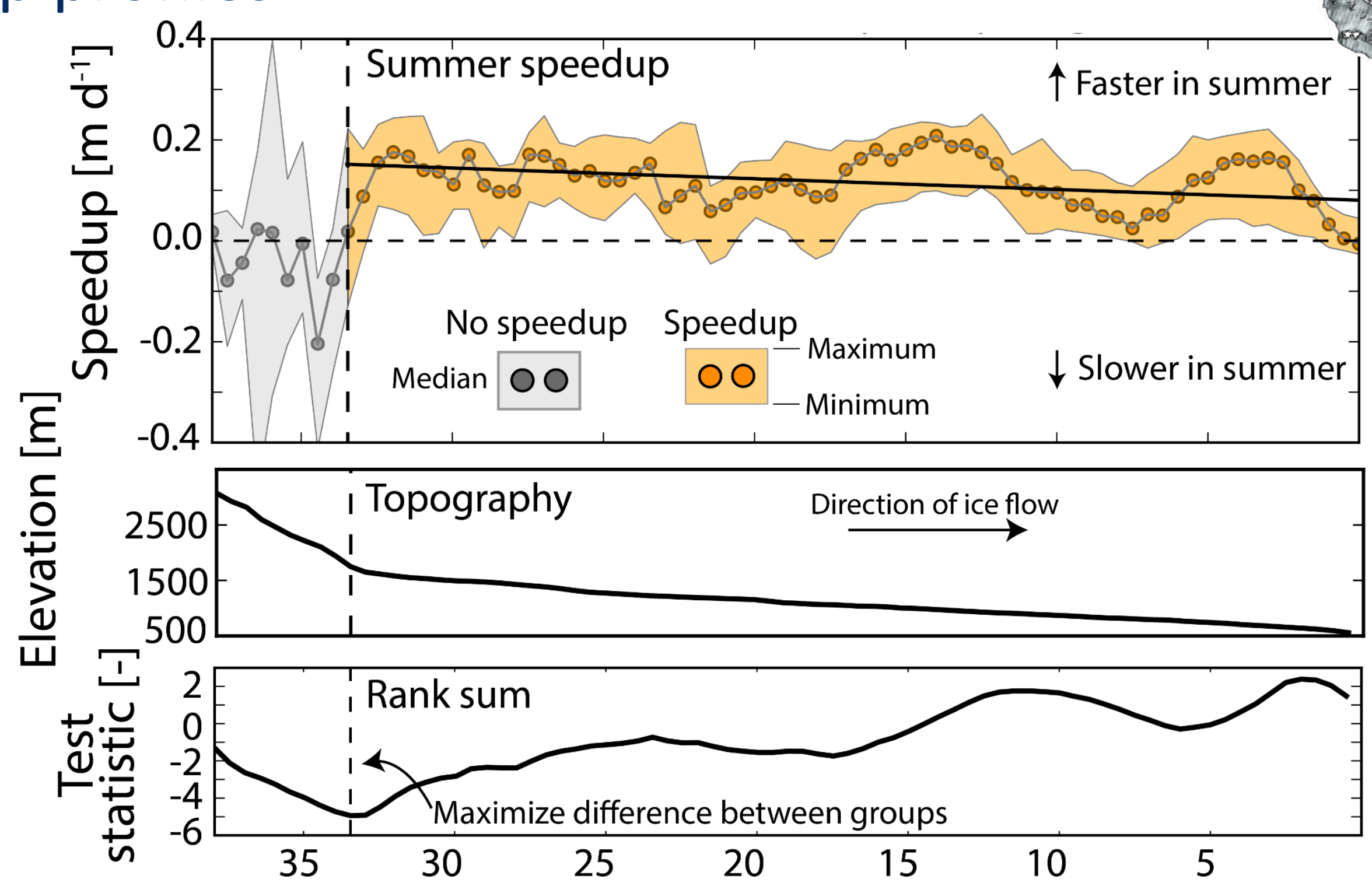




\section{Speedup profiles}

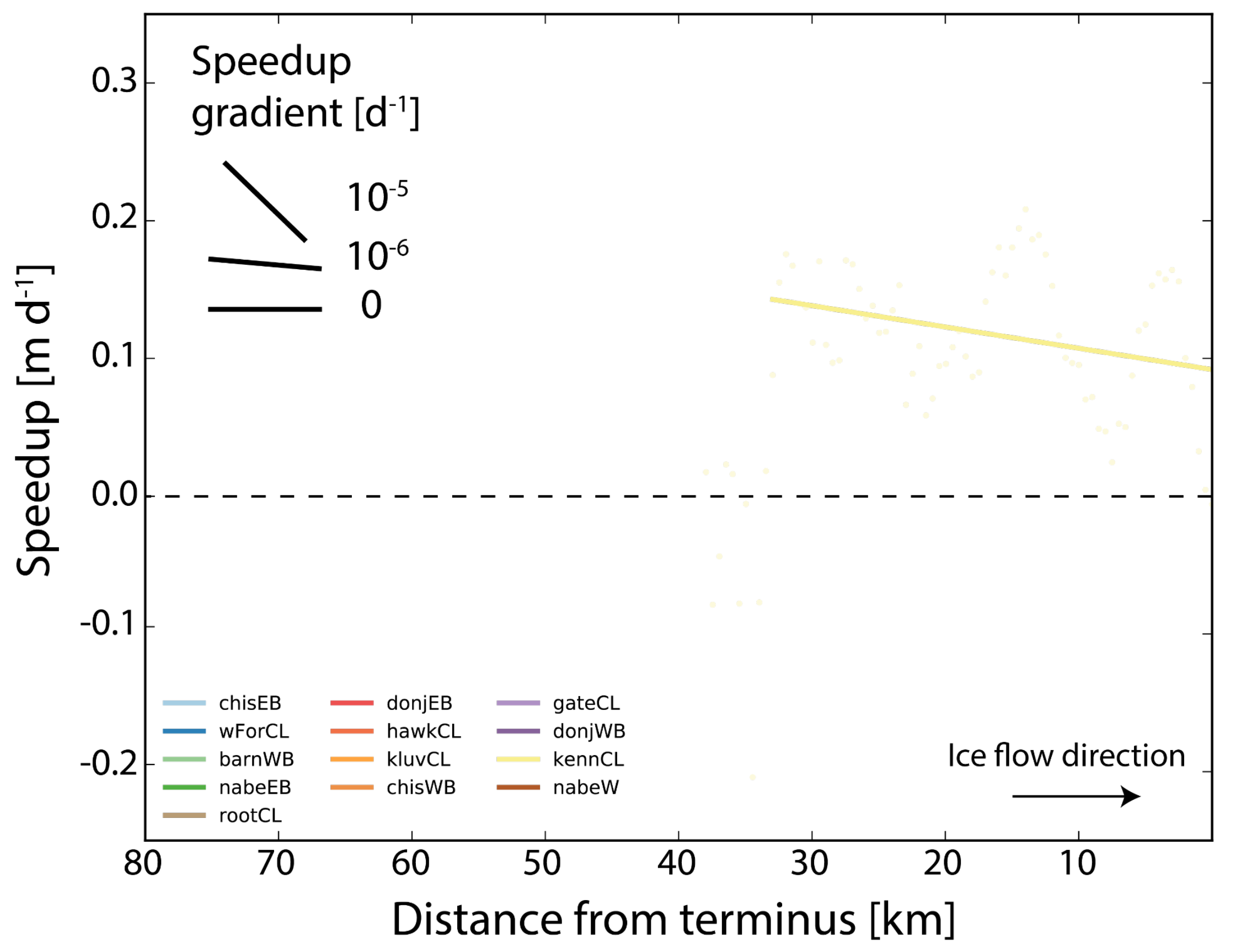




\section{Speedup profiles}

- Identify behavior on $19 / 64$ glaciers

- $0.11 \mathrm{~m} \mathrm{~d}^{-1}$ speedup on average

- Abrupt transition to 0 seasonal change

- Quasi-uniform speedup $3 \times 10^{-6} \mathrm{~d}^{-1}=0.3 \mathrm{~cm} \mathrm{~d}^{-1} \mathrm{~km}^{-1}$

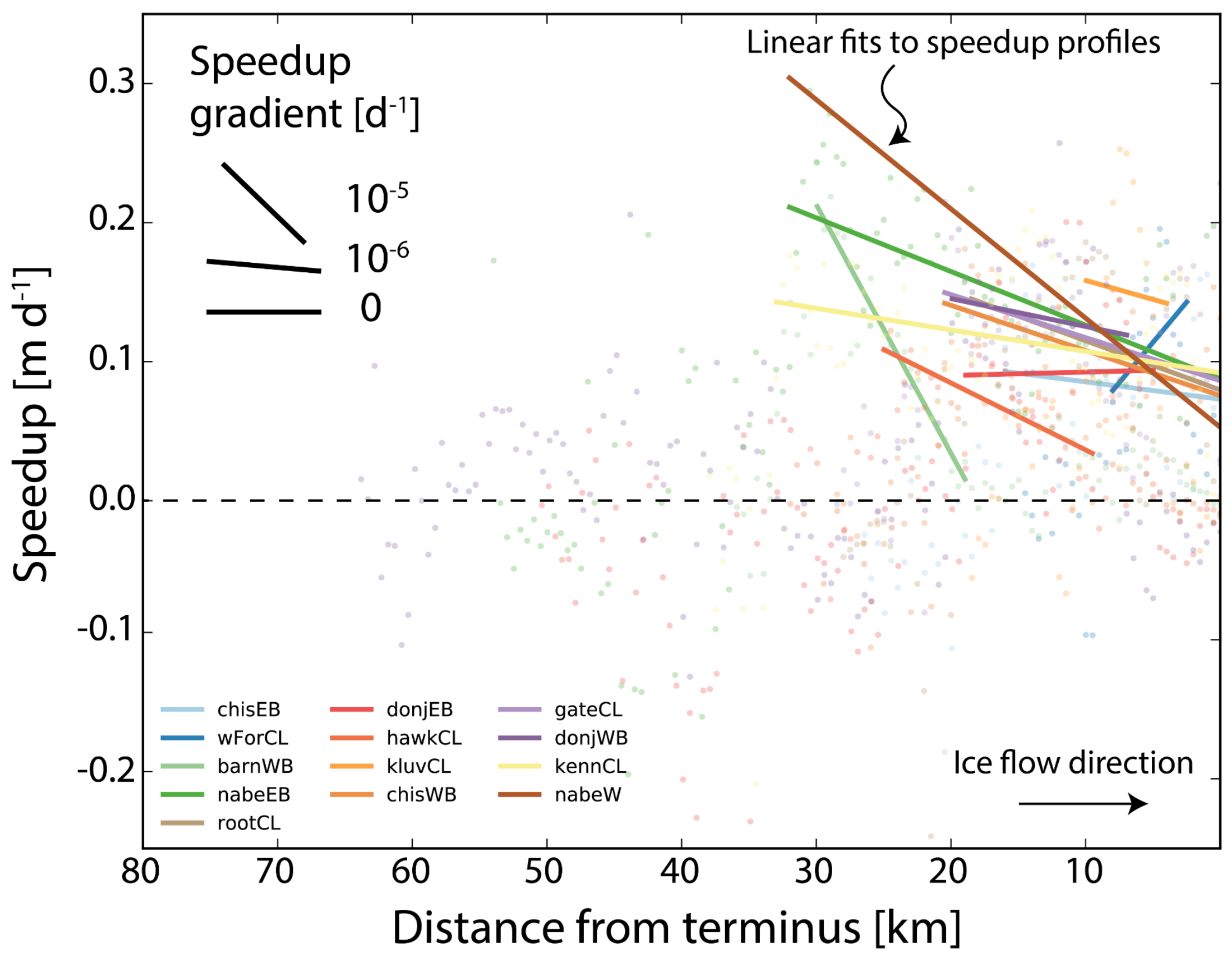




\section{Speedup profiles}

- Identify behavior on $19 / 64$ glaciers

- $0.11 \mathrm{~m} \mathrm{~d}^{-1}$ speedup on average

- Abrupt transition to 0 seasonal change

- Quasi-uniform speedup $3 \times 10^{-6} \mathrm{~d}^{-1}=0.3 \mathrm{~cm} \mathrm{~d}^{-1} \mathrm{~km}^{-1}$

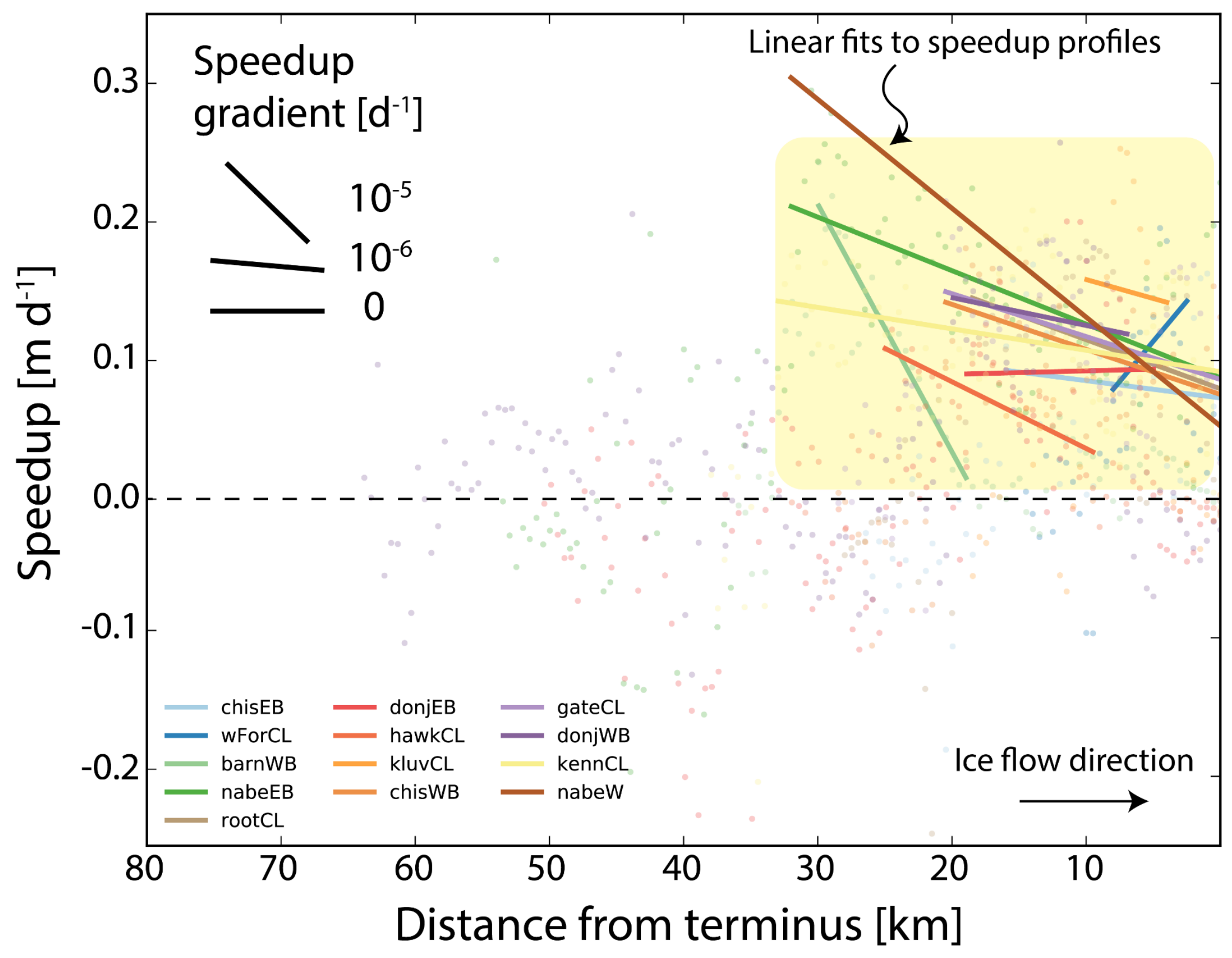




\section{Speedup profiles}

- Identify behavior on $19 / 64$ glaciers

- $0.11 \mathrm{~m} \mathrm{~d}^{-1}$ speedup on average

- Abrupt transition to 0 seasonal change

- Quasi-uniform speedup $3 \times 10^{-6} \mathrm{~d}^{-1}=0.3 \mathrm{~cm} \mathrm{~d}^{-1} \mathrm{~km}^{-1}$

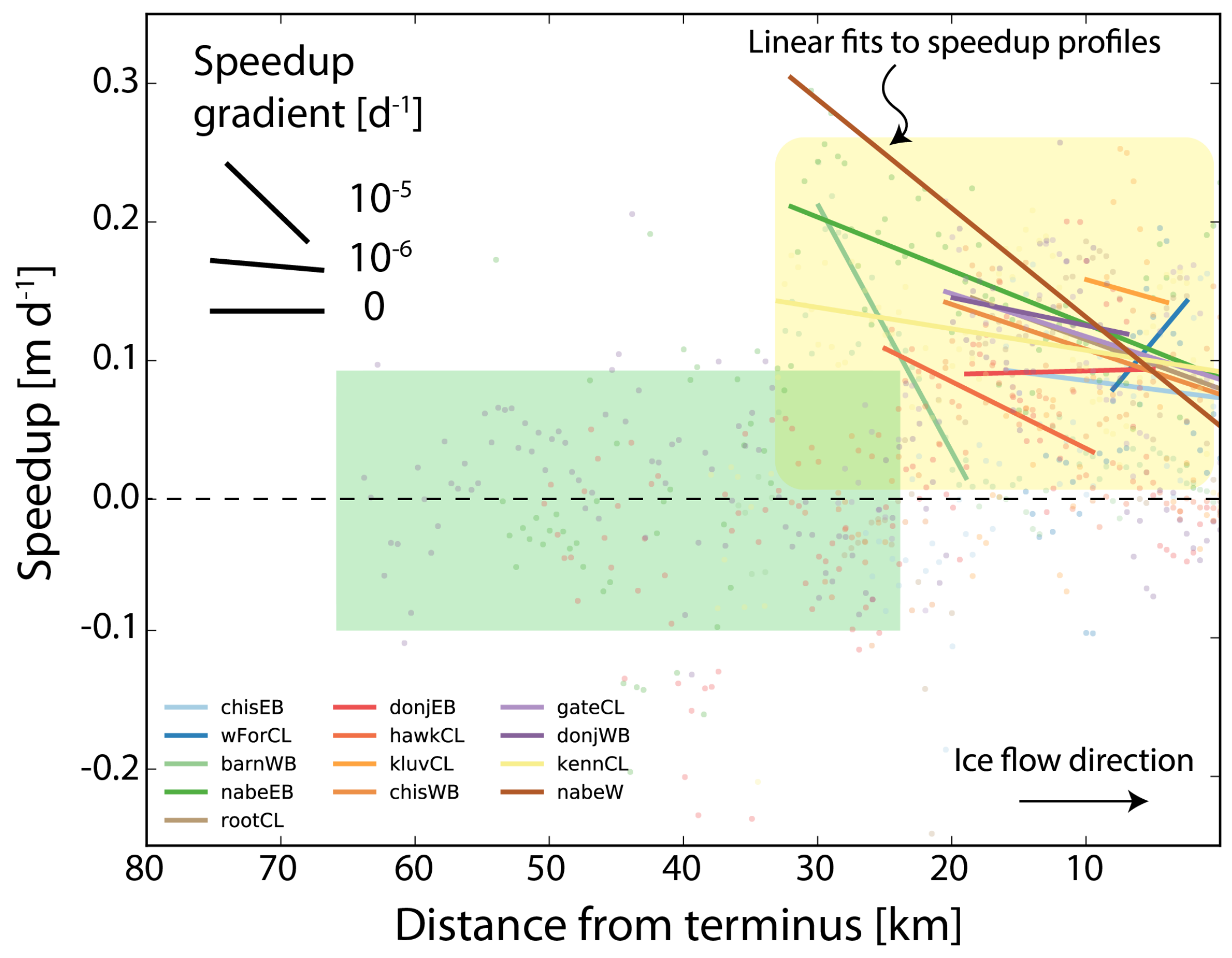




\section{Speedup profiles}

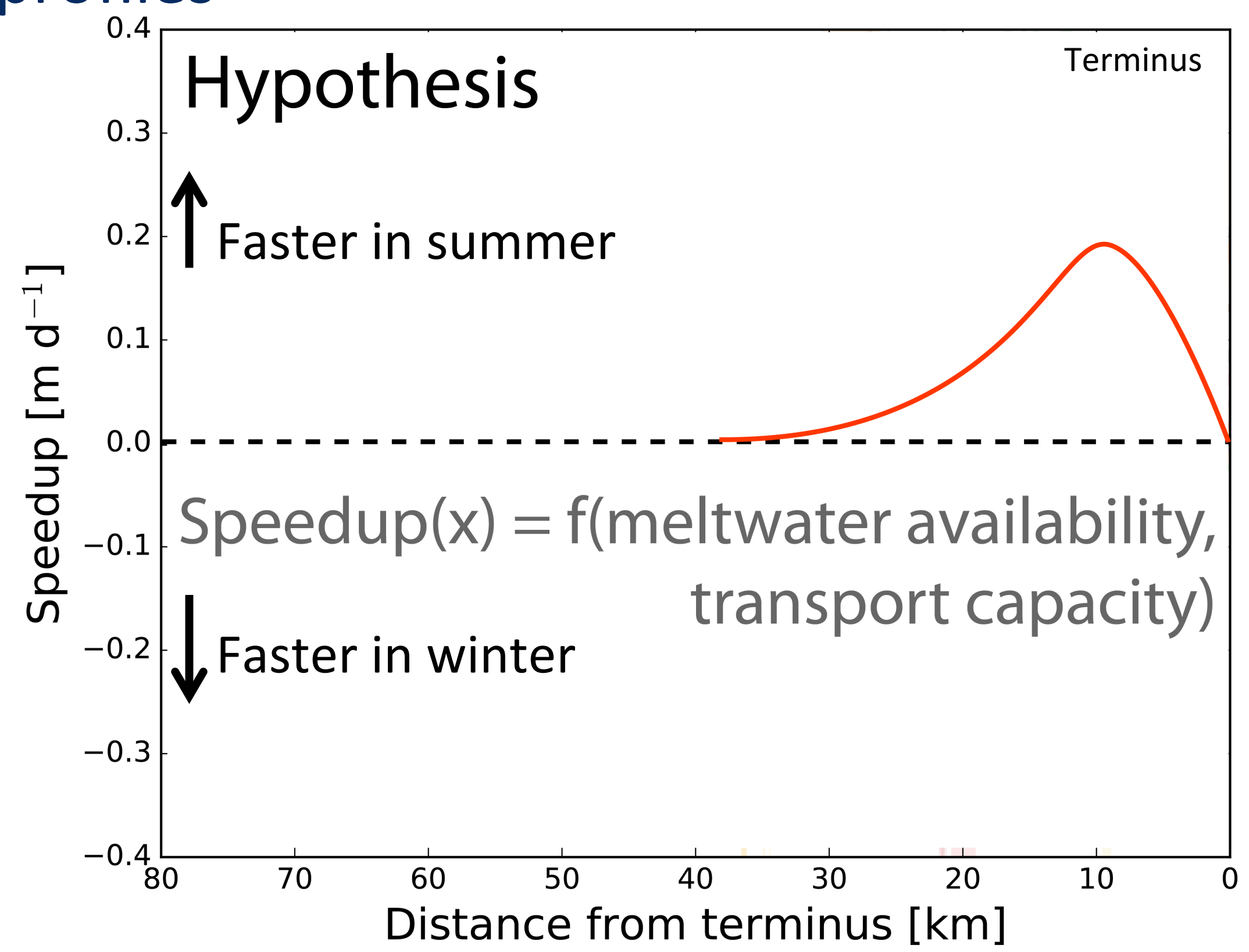




\section{Speedup profiles}

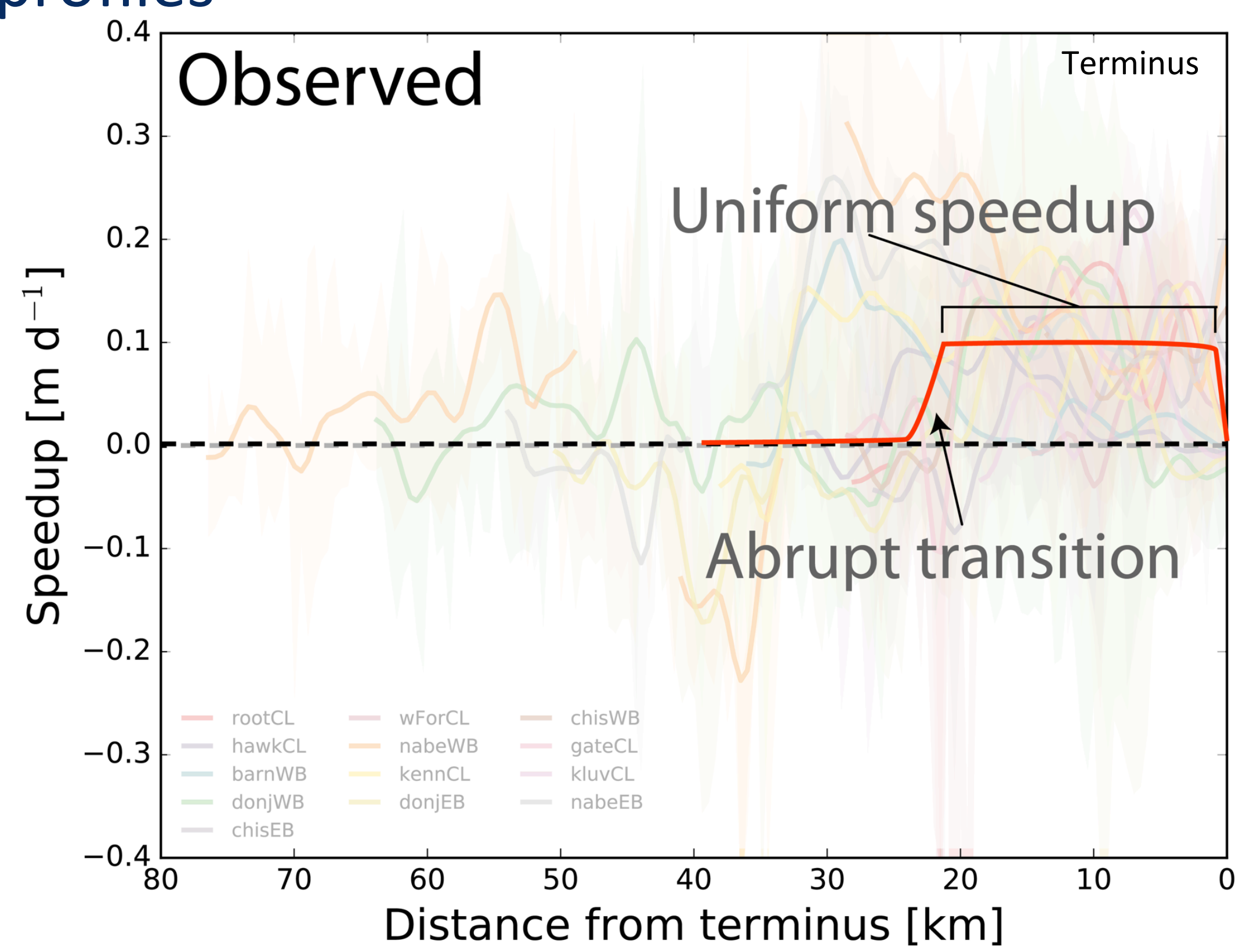




\section{Speedup scaling

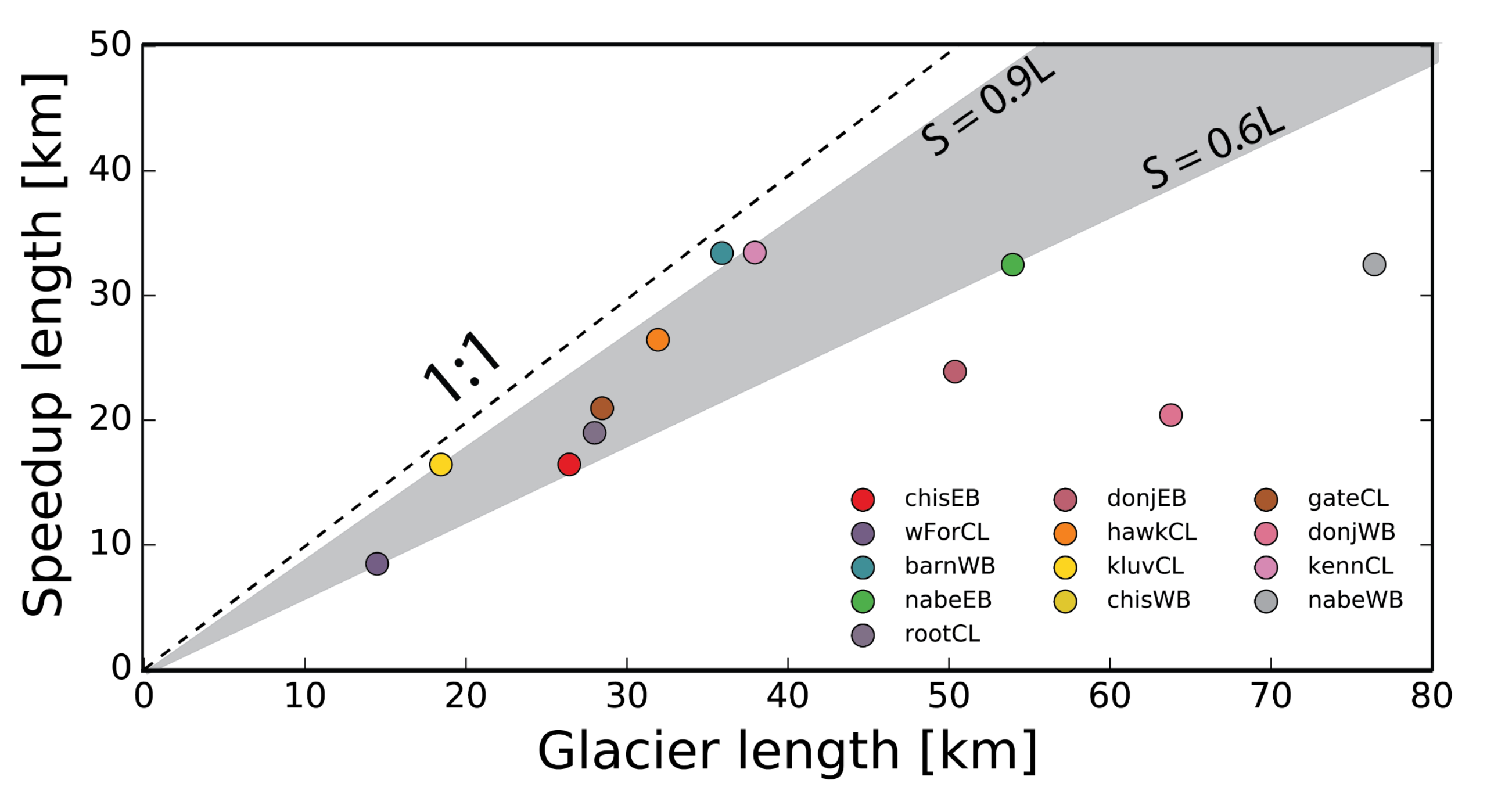$$
\text { (n) }
$$ 


\section{Controls on speedup length}

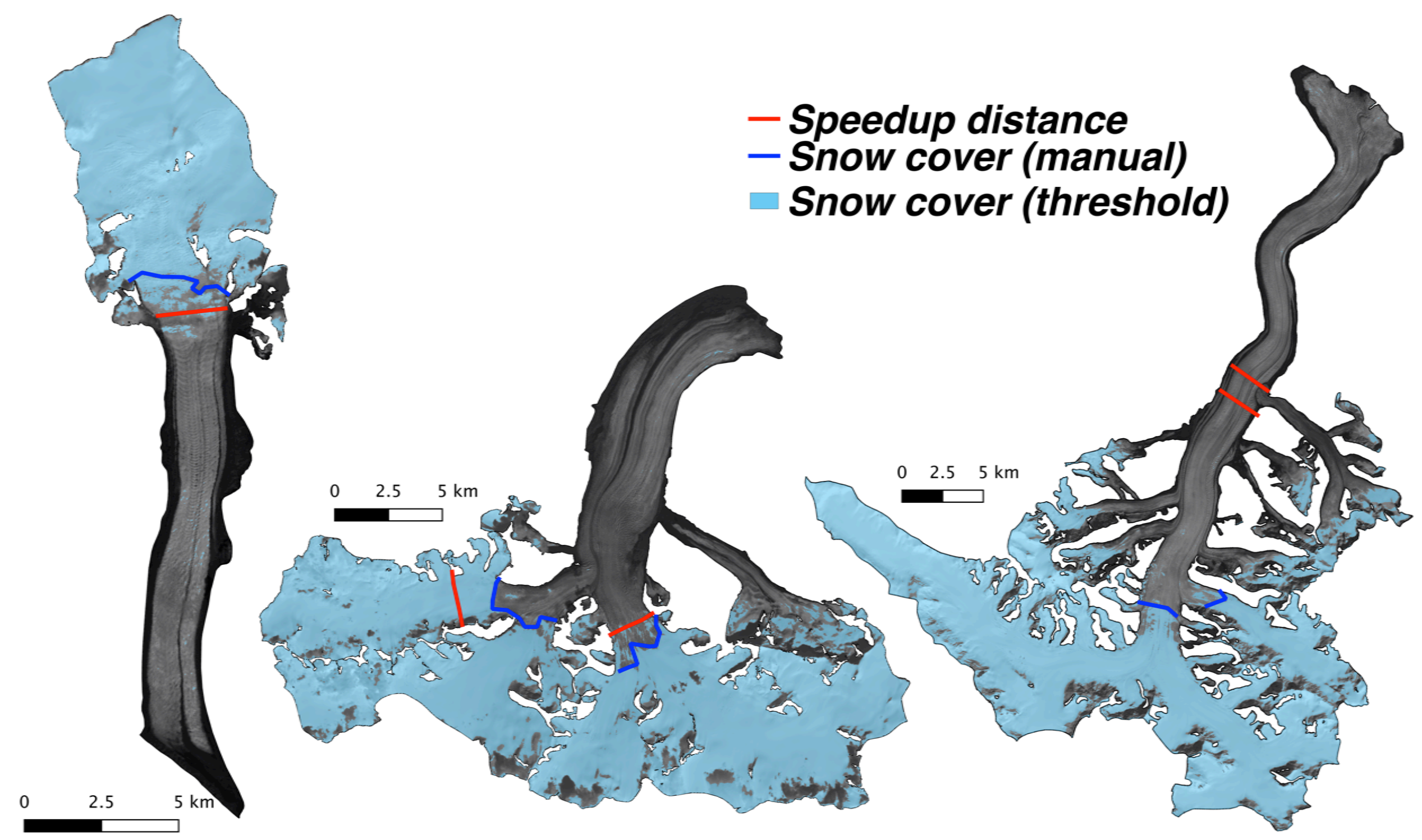




\section{Elevation distribution}
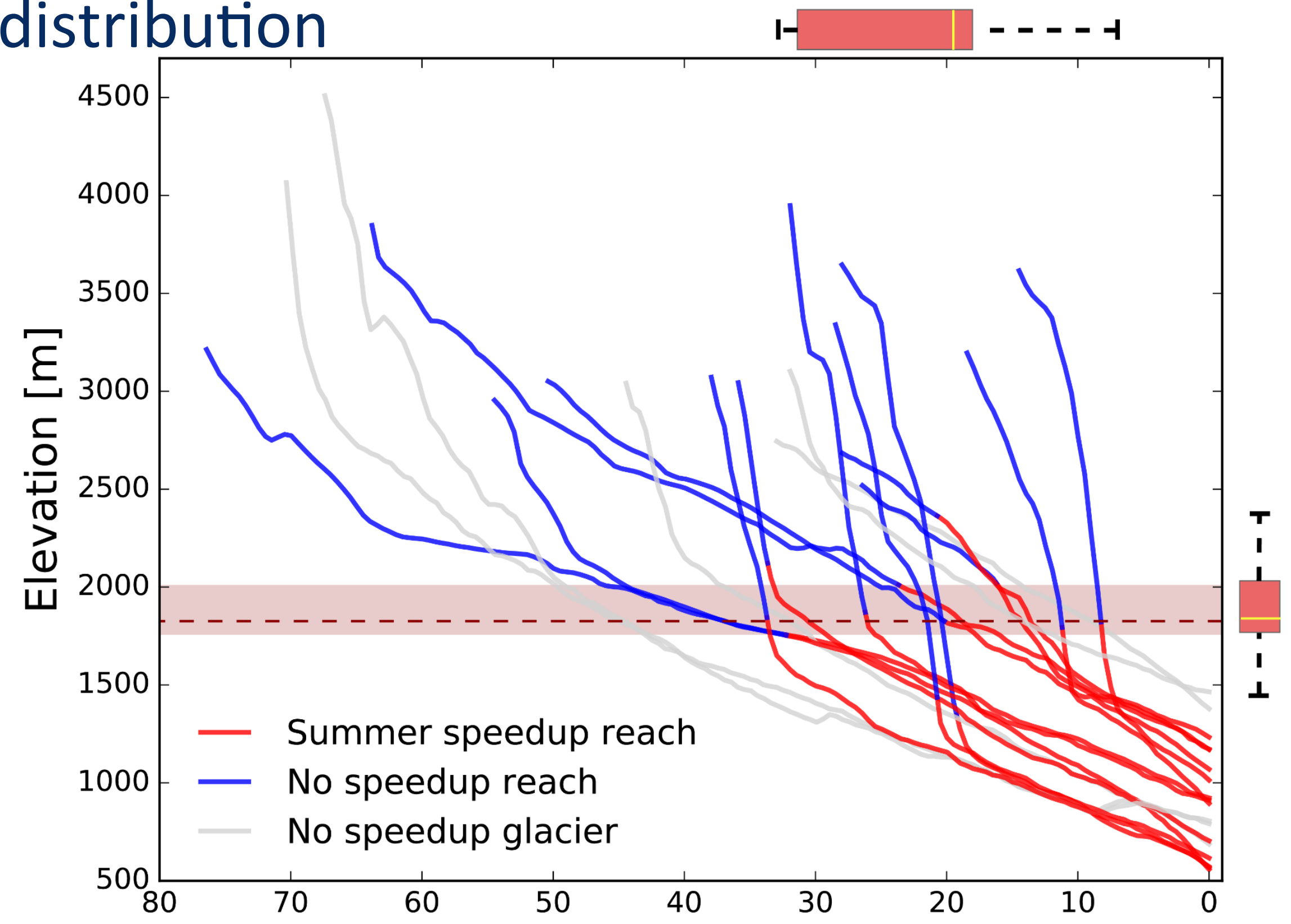

Armstrong et al. [2017], Geophys. Res. Lett. Distance from terminus [km] 


\section{Icefall evolution}

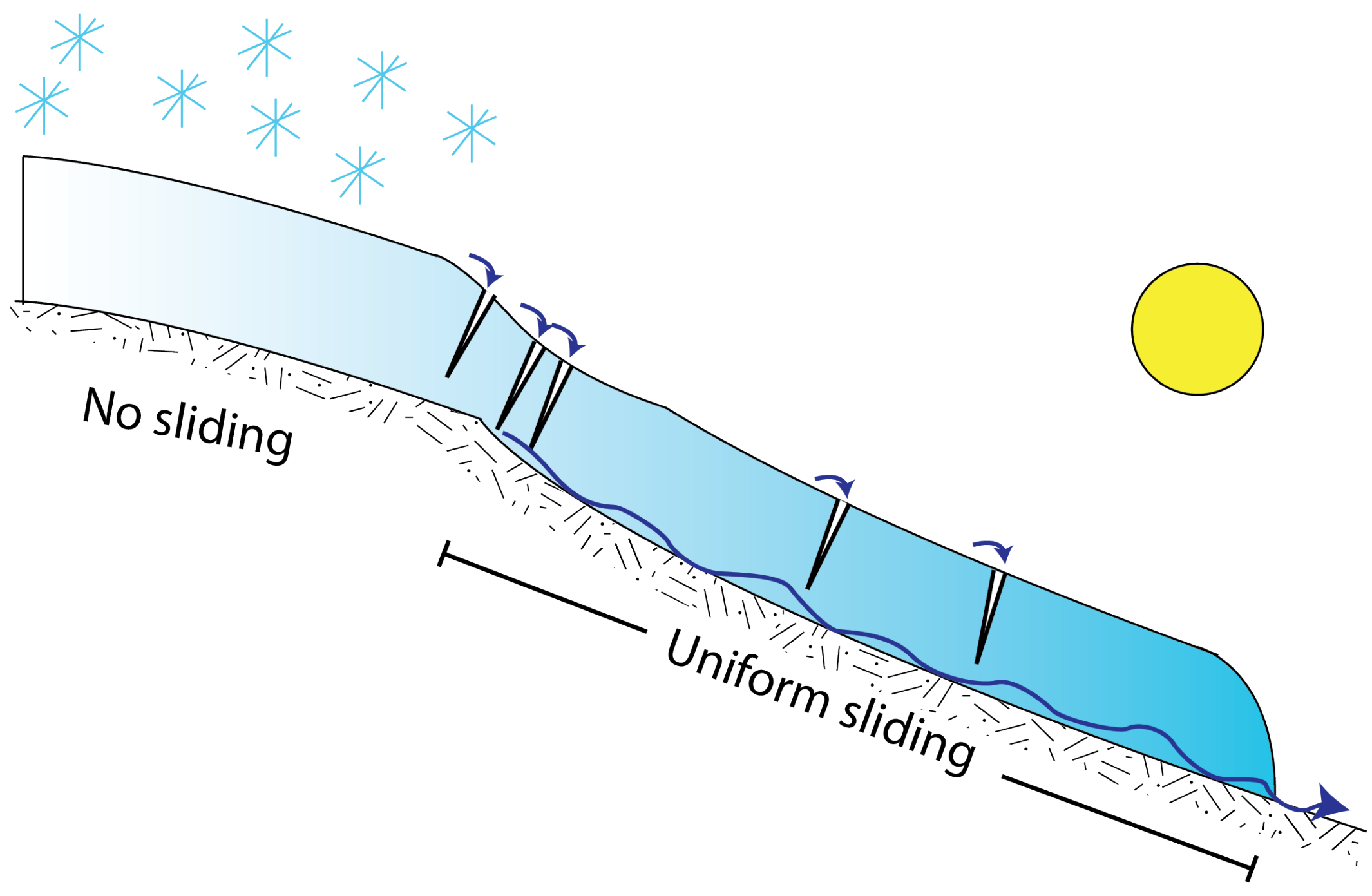




\section{Icefall evolution}

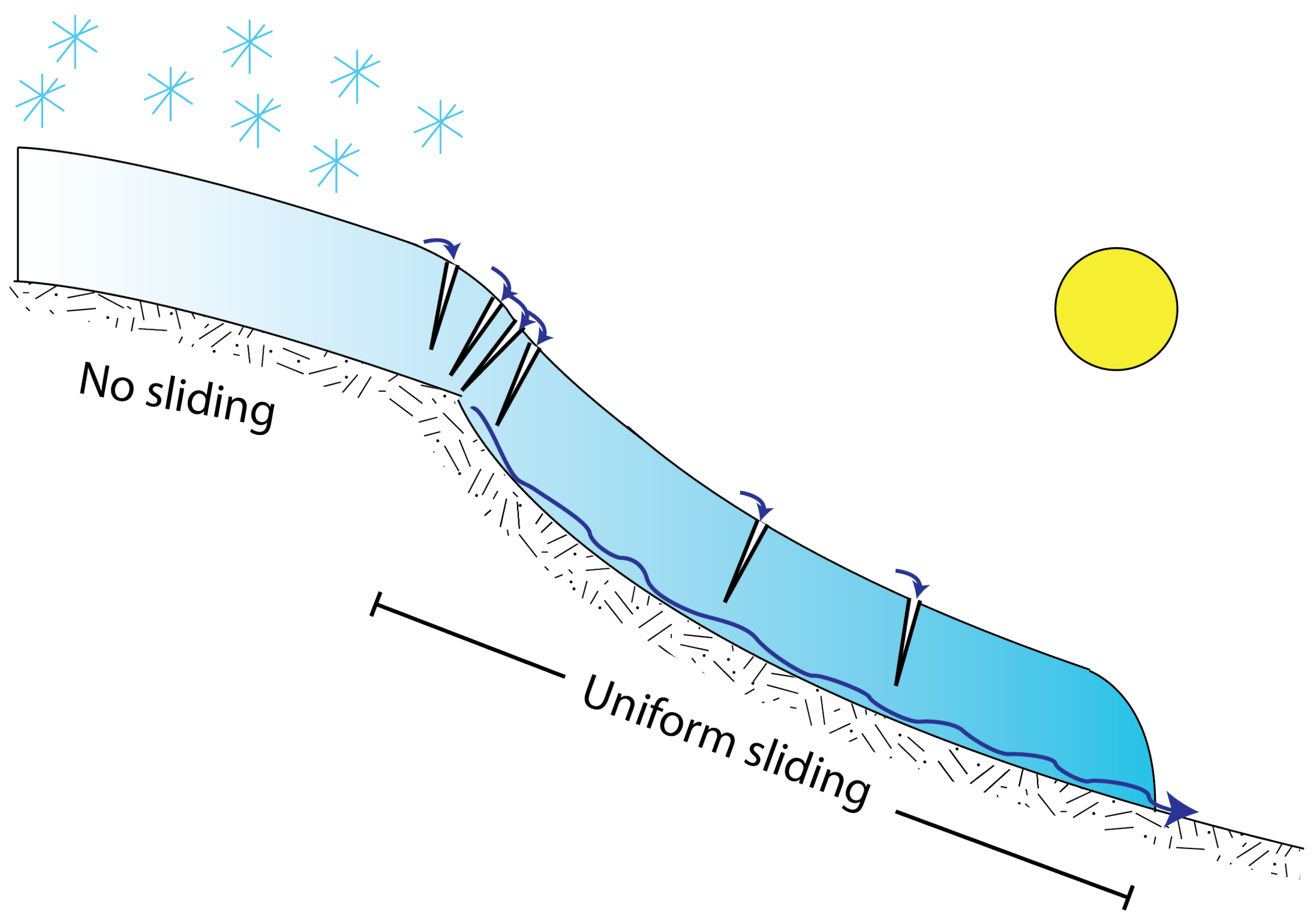




\section{Icefall evolution}

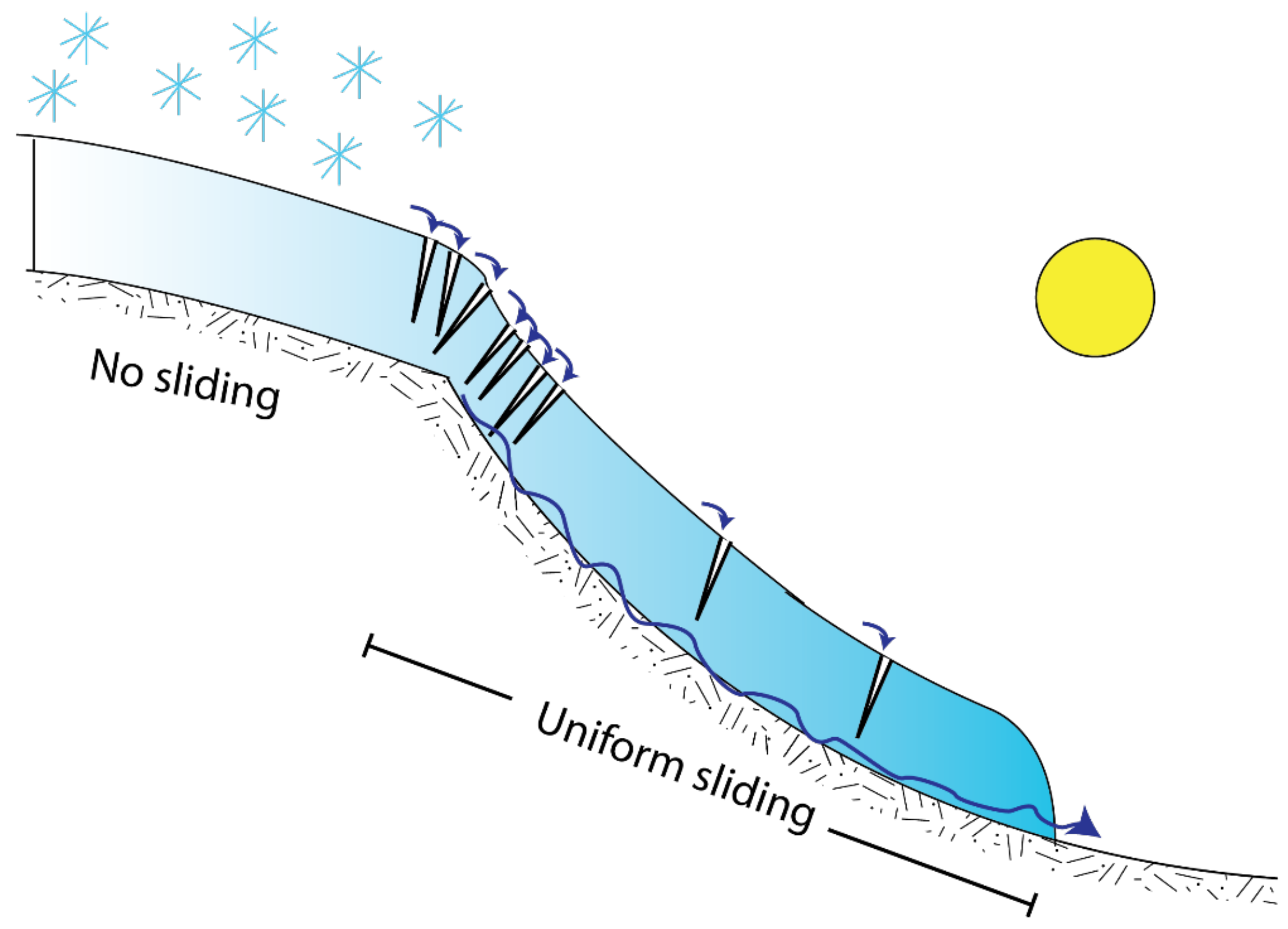




\section{Conclusions}

- Uniform summer speedup over $10 \mathrm{~s}$ of $\mathrm{km}$, with hint of upglacier limit

- Association of speedup length and icefall location change in dynamics?

- Feedback for icefall formation?
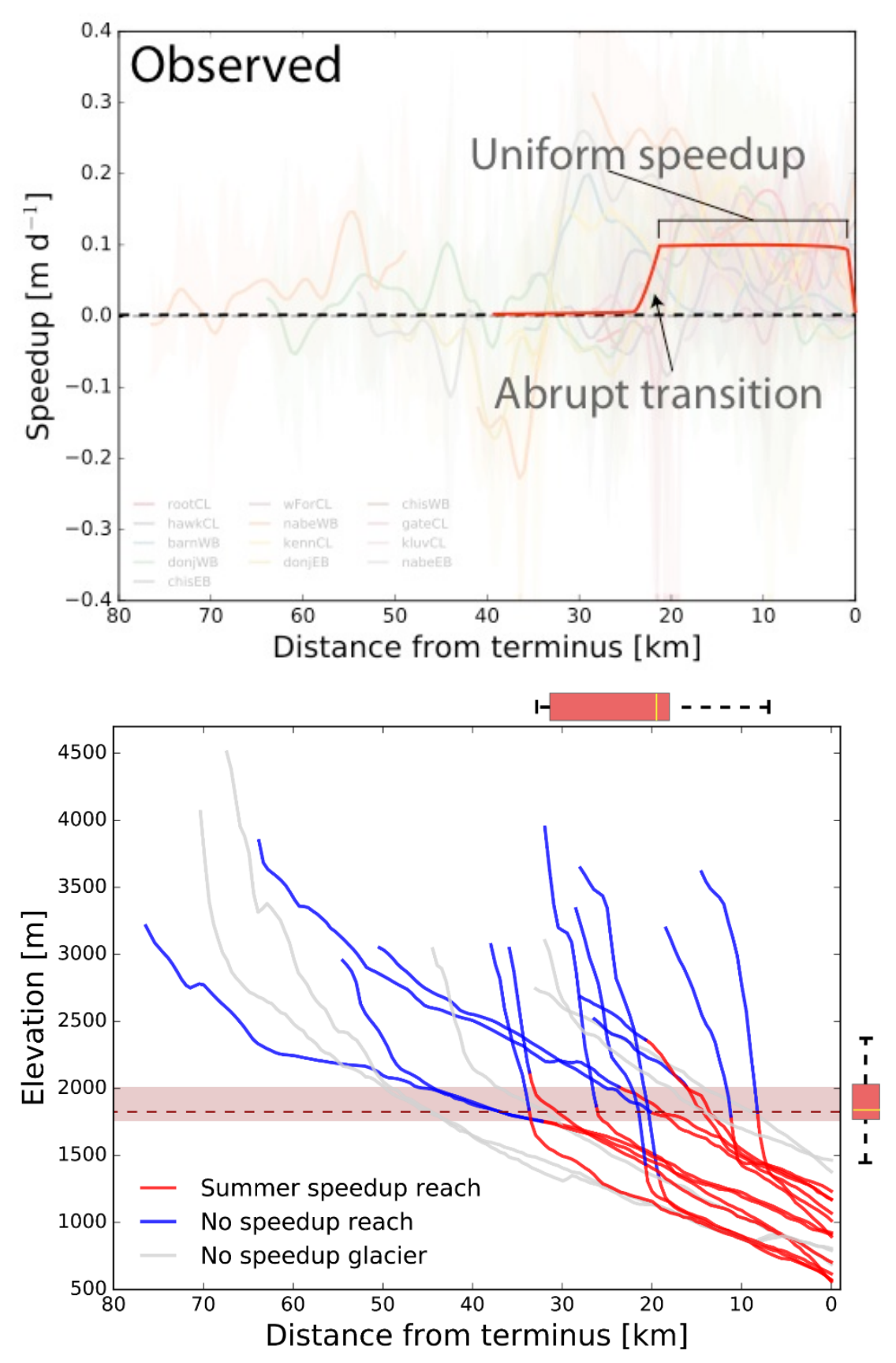


\section{Thanks!}






\section{Spatial distribution}
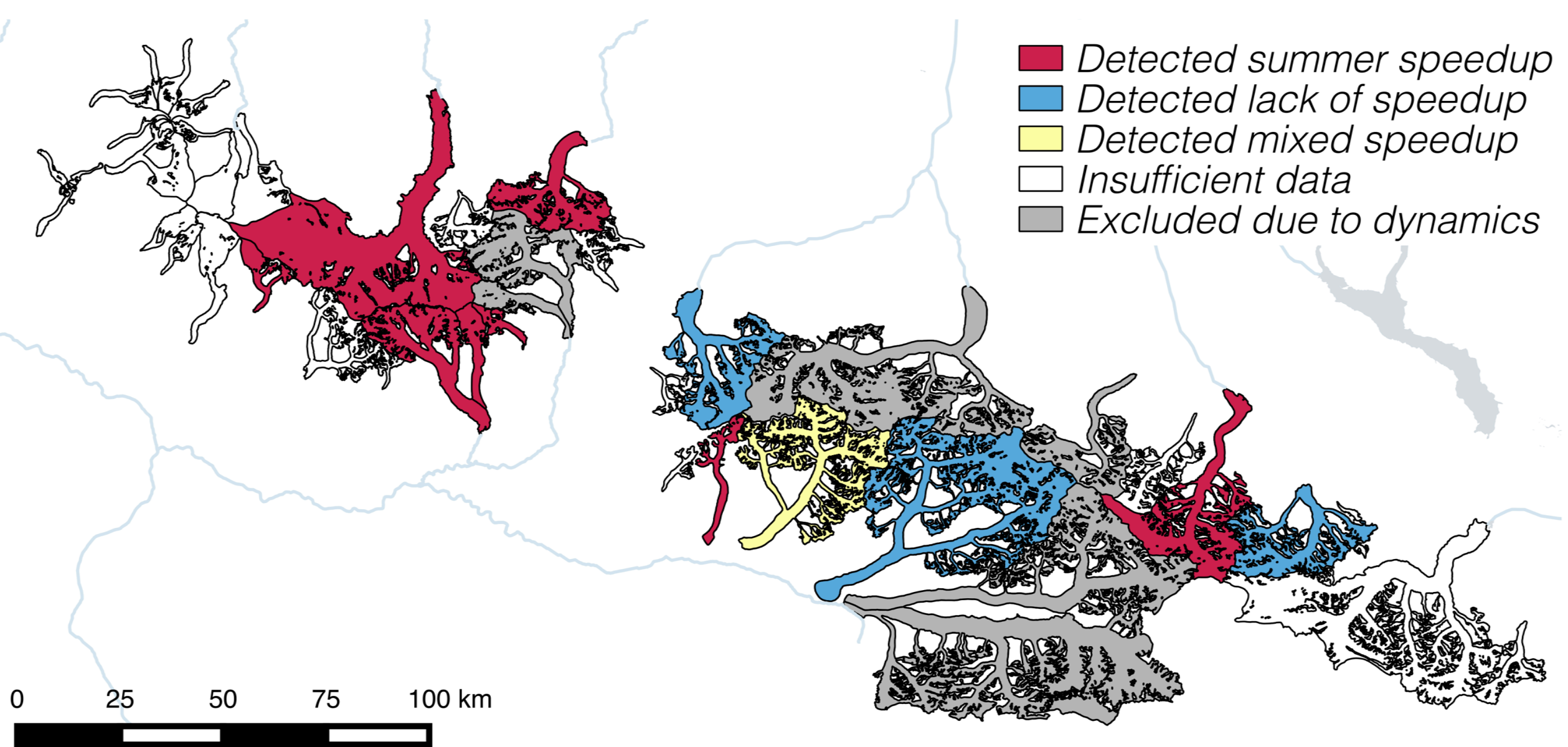


\section{Icefalls and snowline}

- Difficult to disentangle from snowline

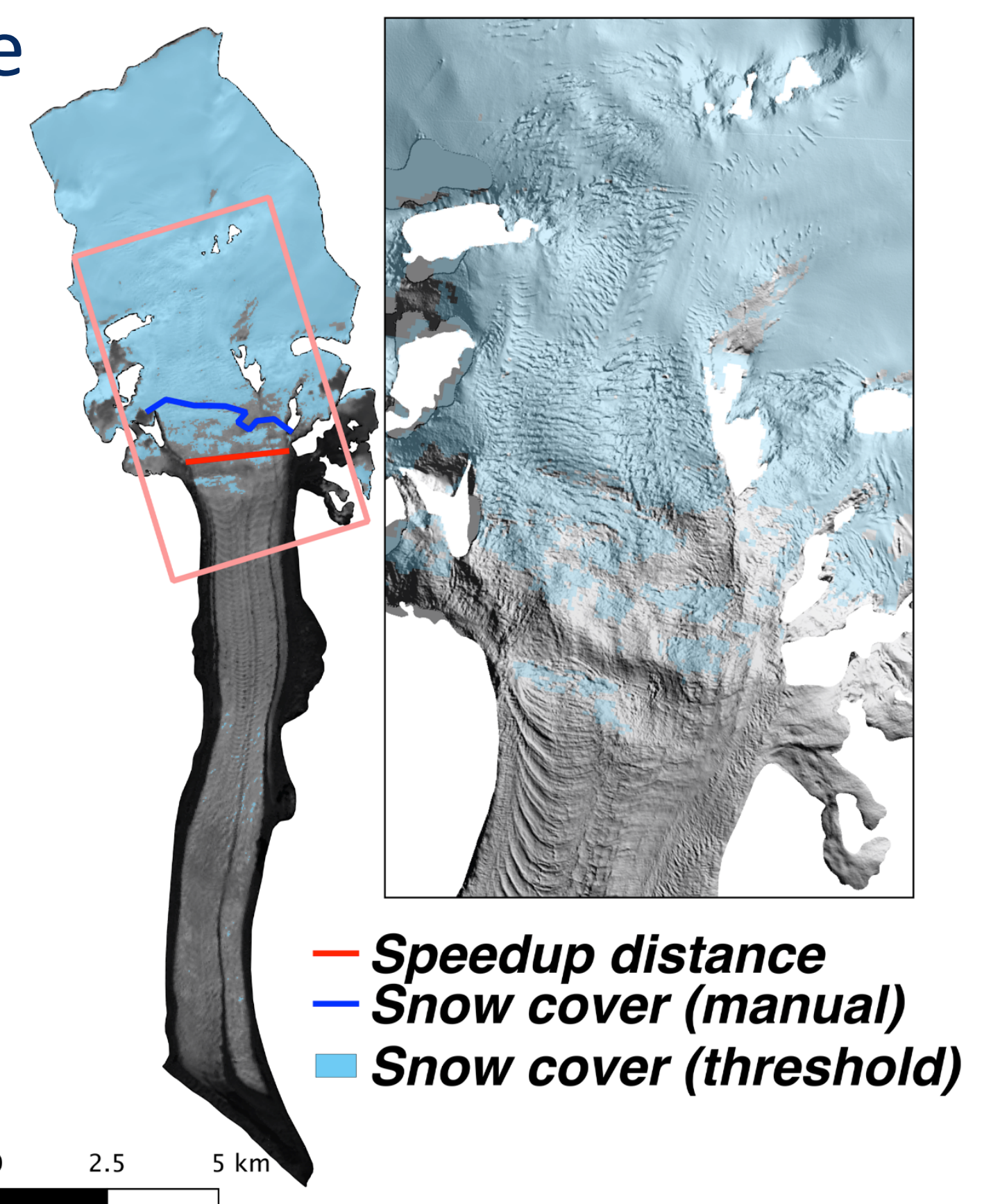




\section{Image cross-correlation}

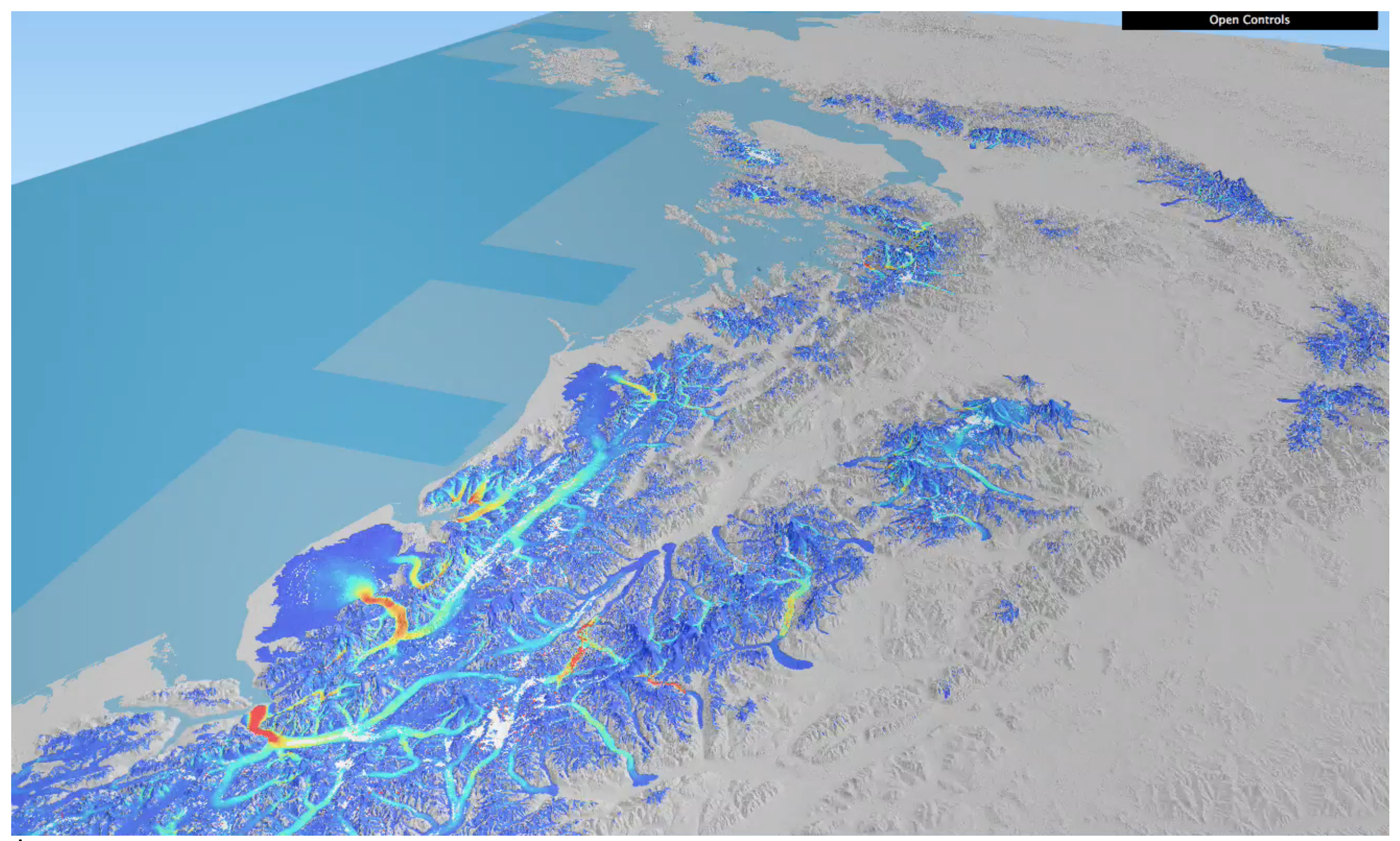


Association with late summer snowline

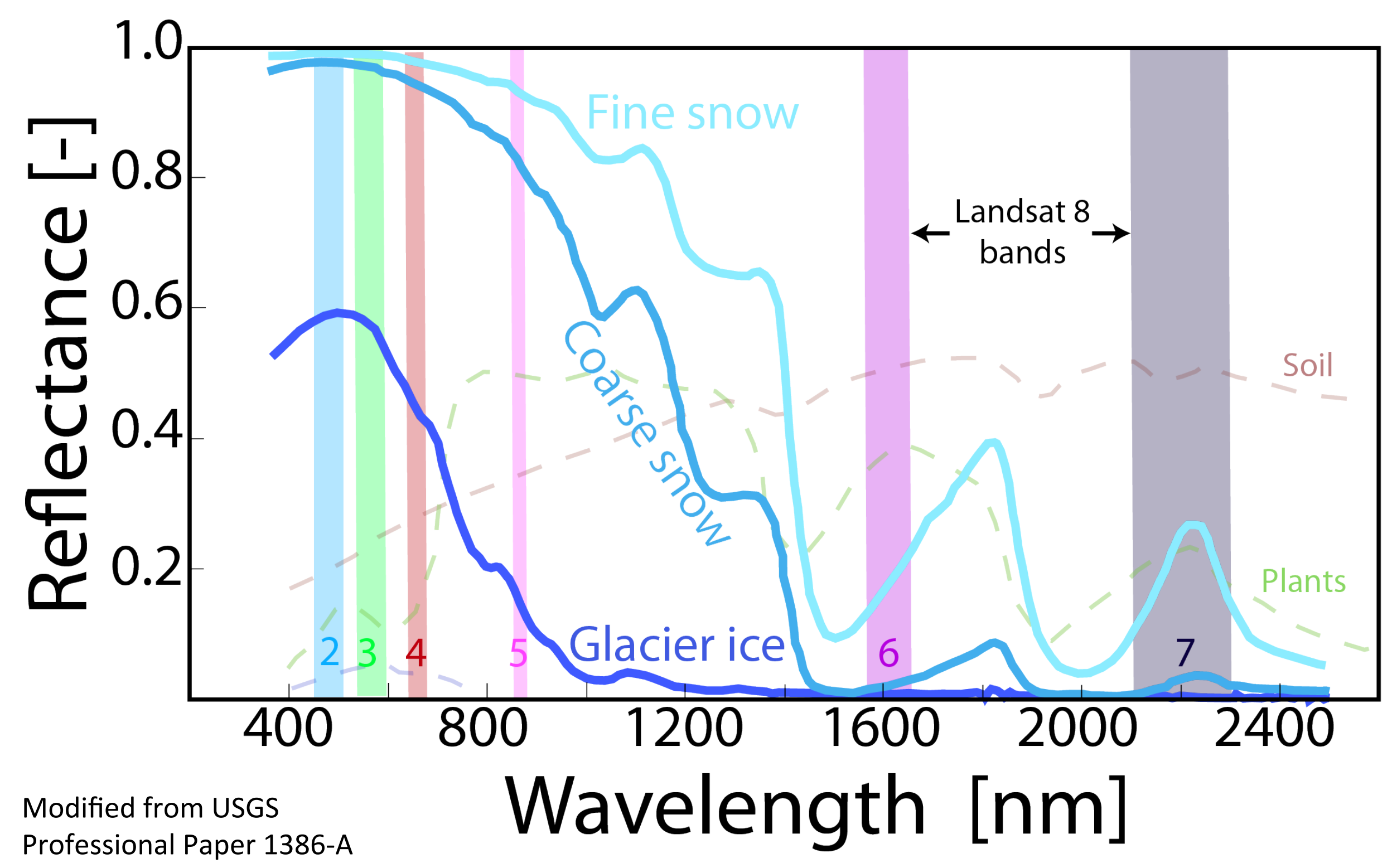




\section{Lake-terminating glaciers}

\section{Regal centerline}
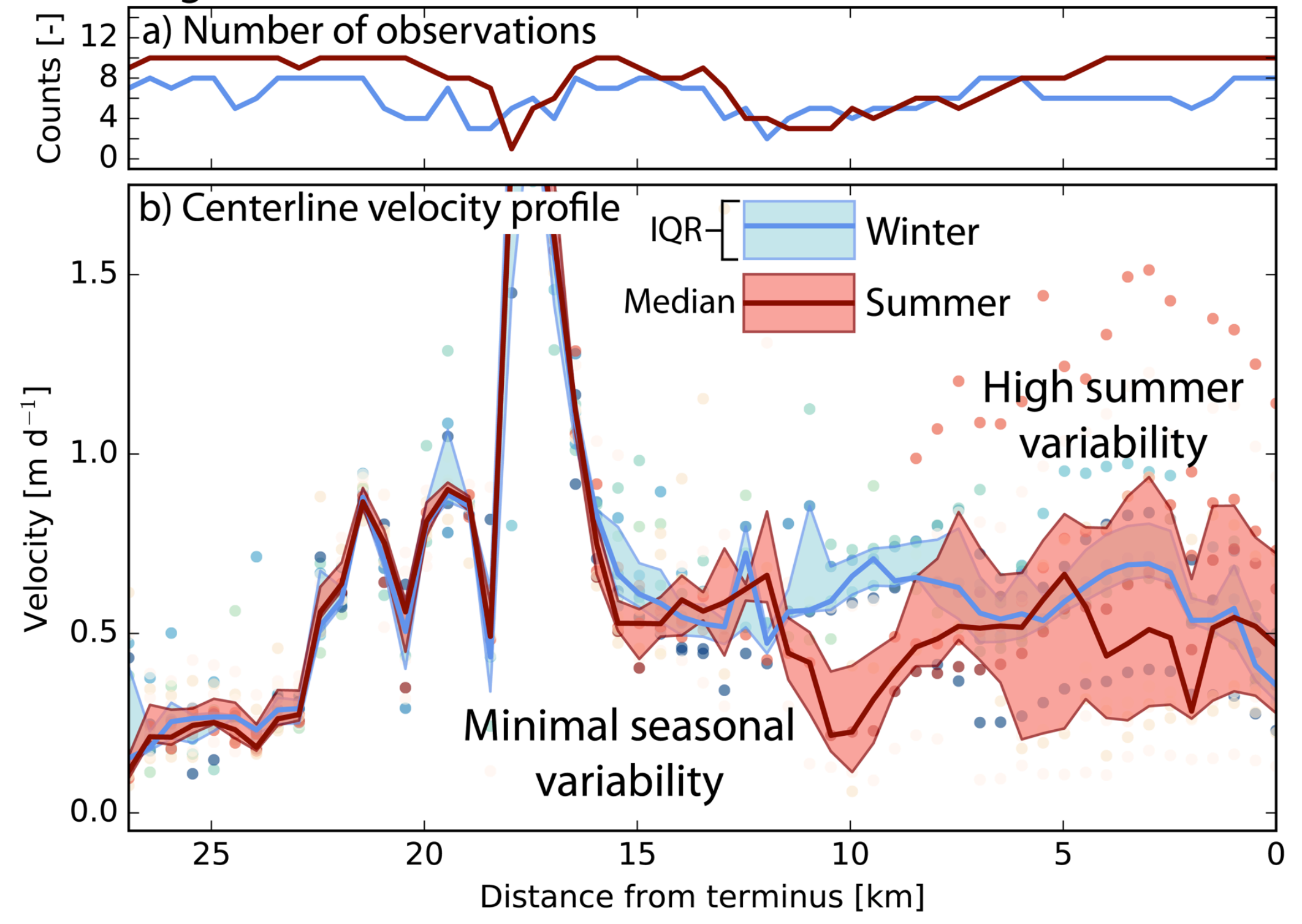


\section{Scientific context}
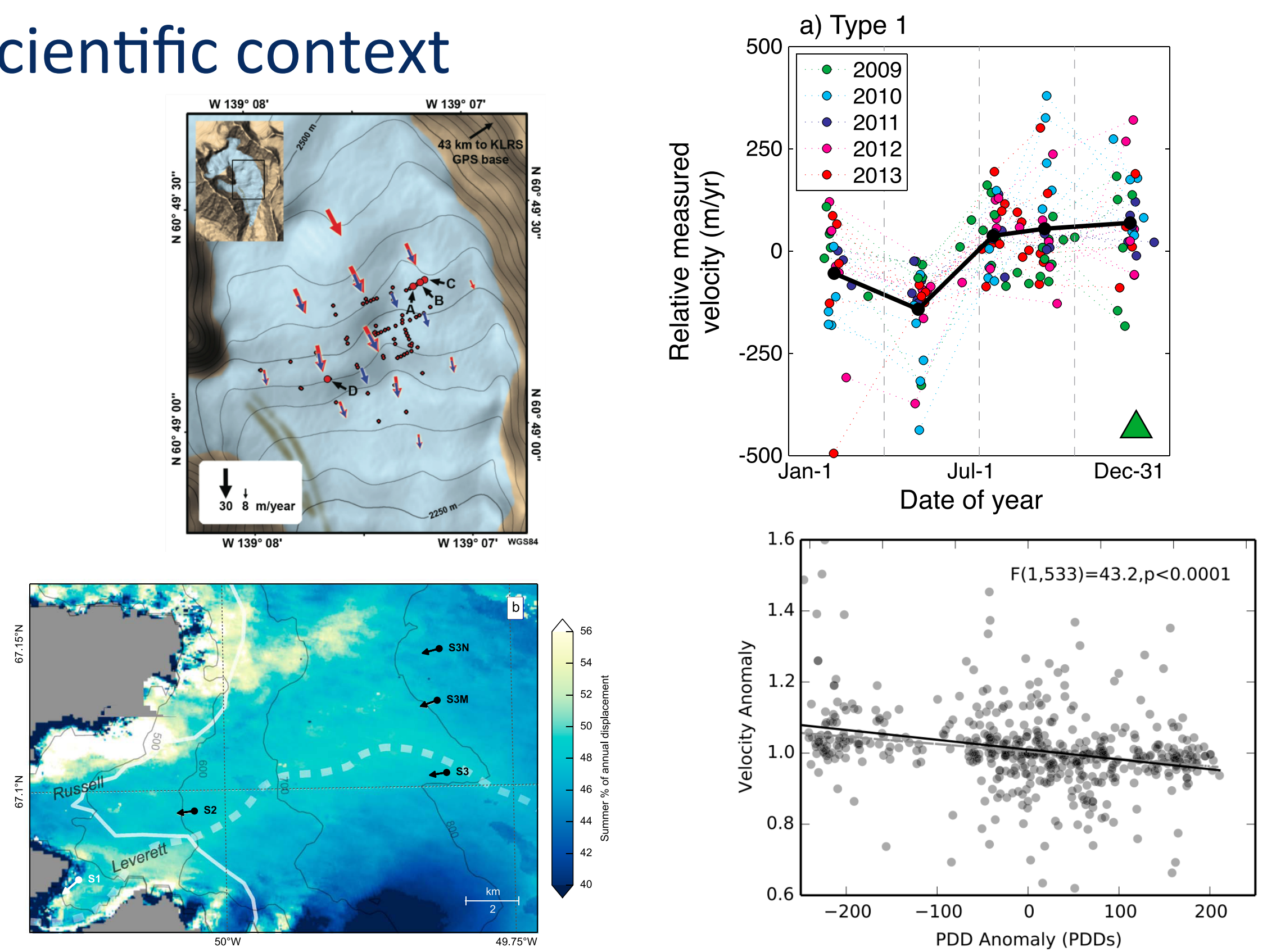

Figures modified from Burgess et al. [2013]; Flowers et al. [2014]; Moon et al. [2014]; Tedstone et al. [2014] 


\section{Swath filtering}

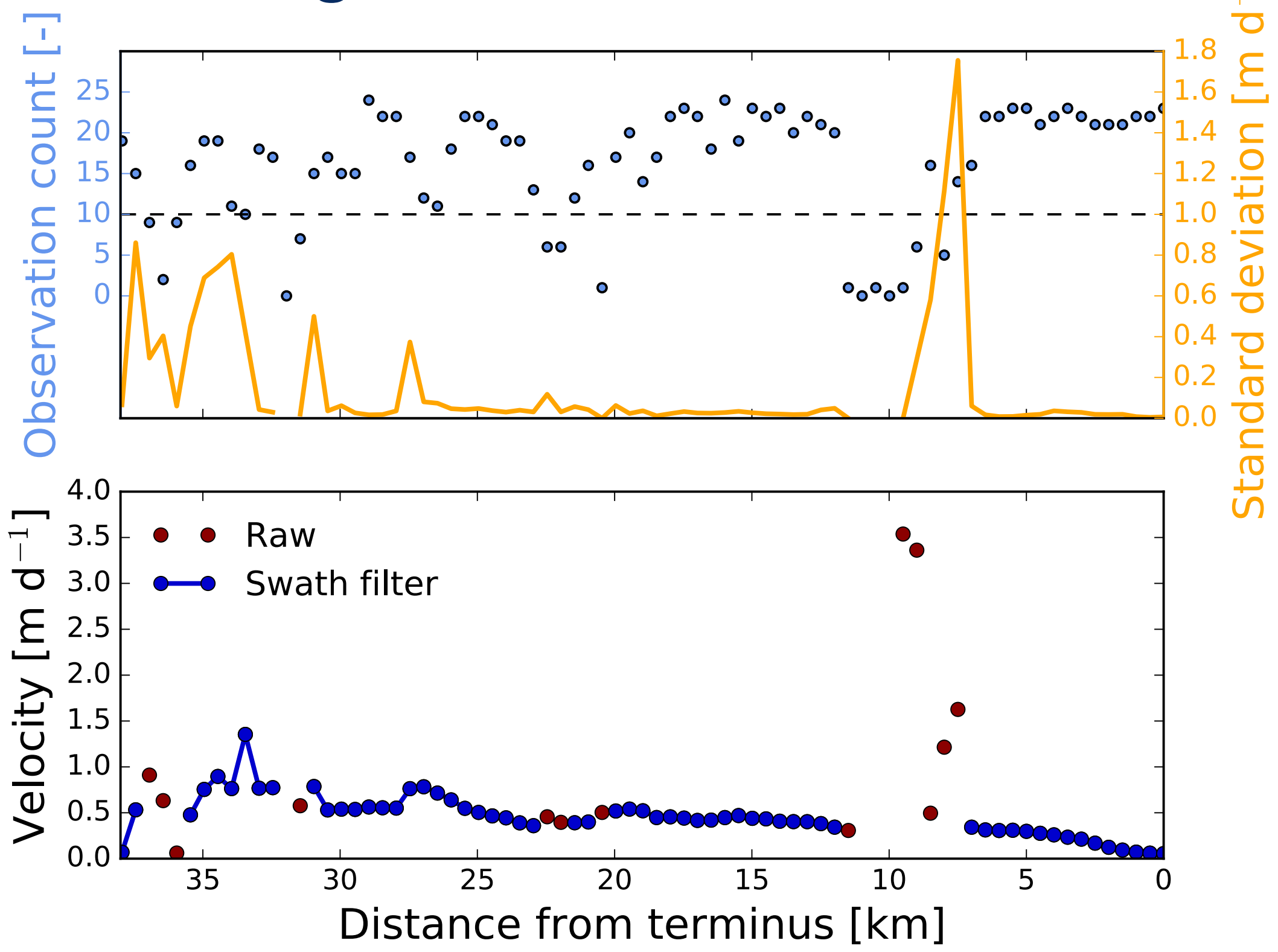




\section{Temporal filtering}

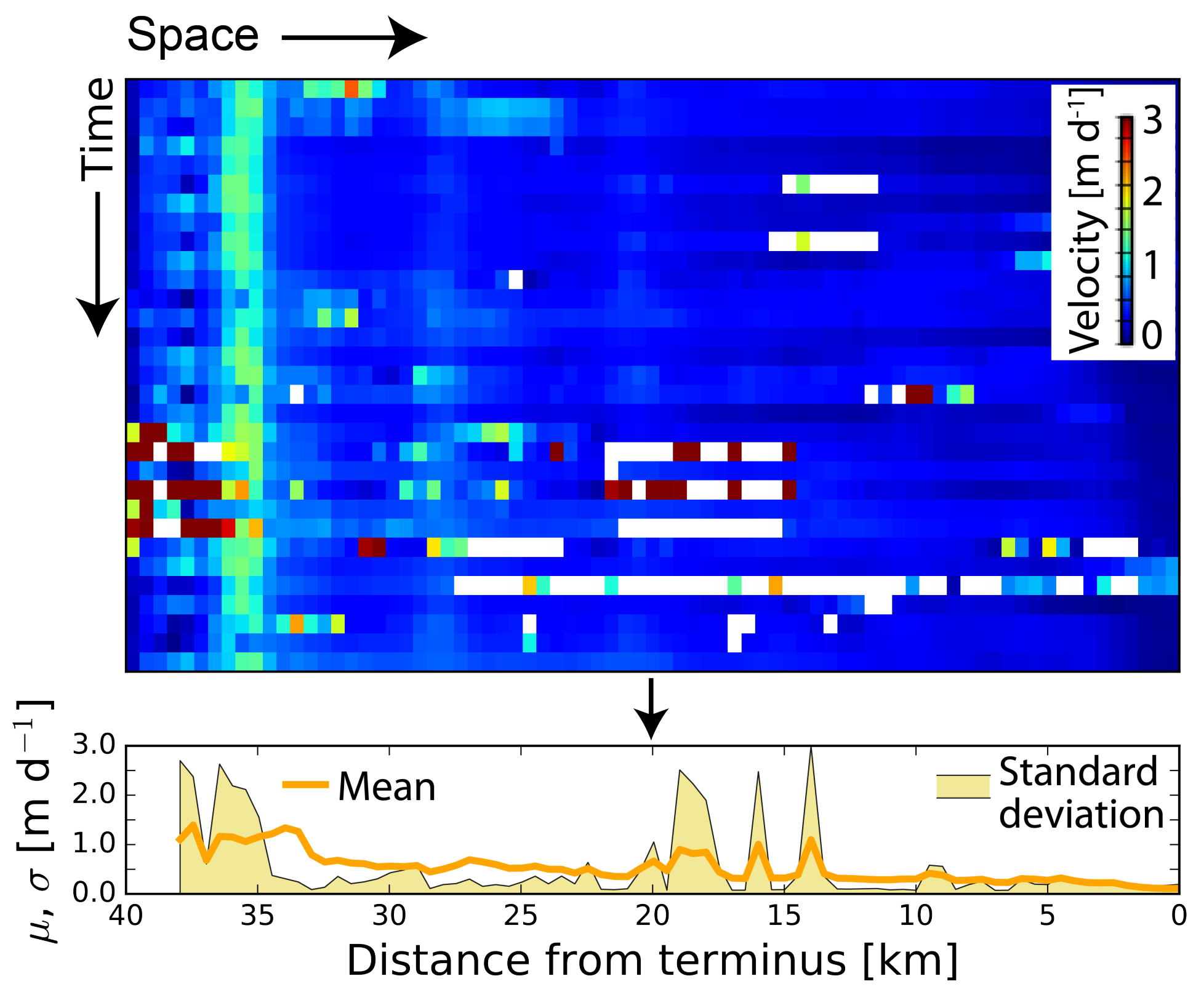




\section{Filtering methods}

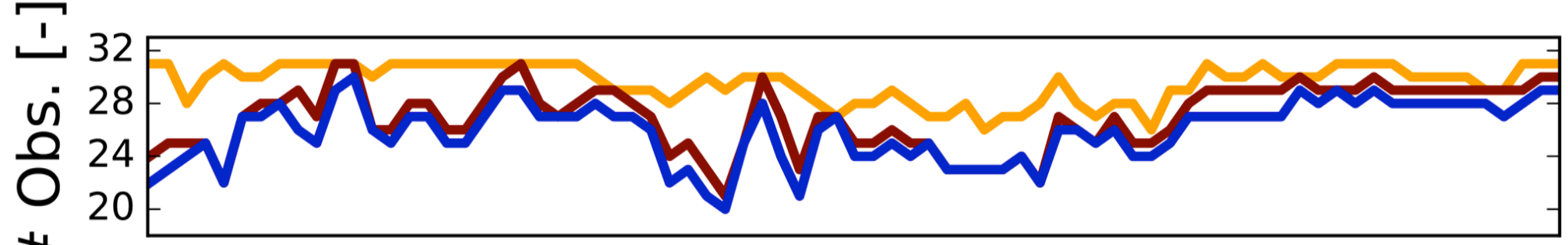
\#

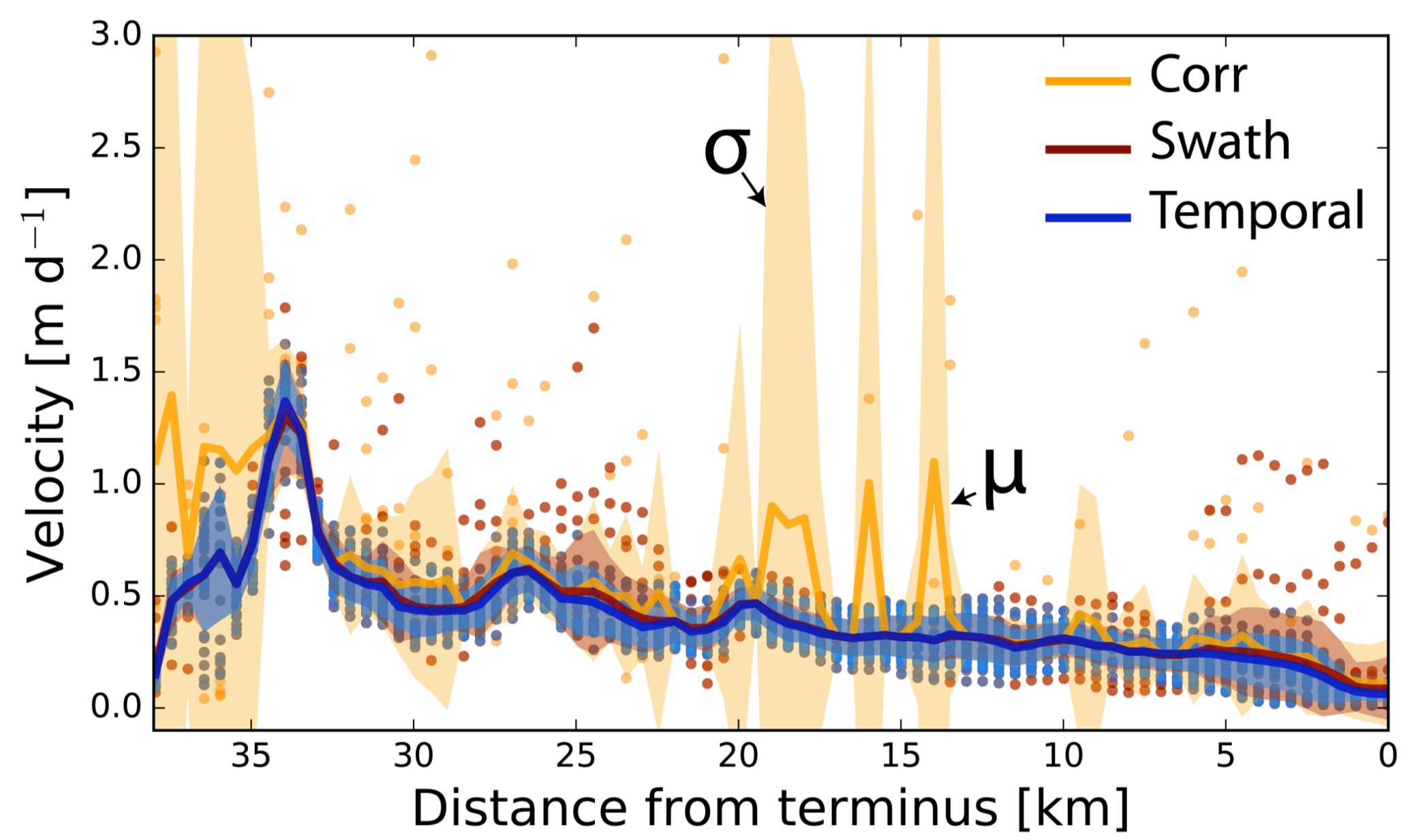




\section{Normalized speedup length}

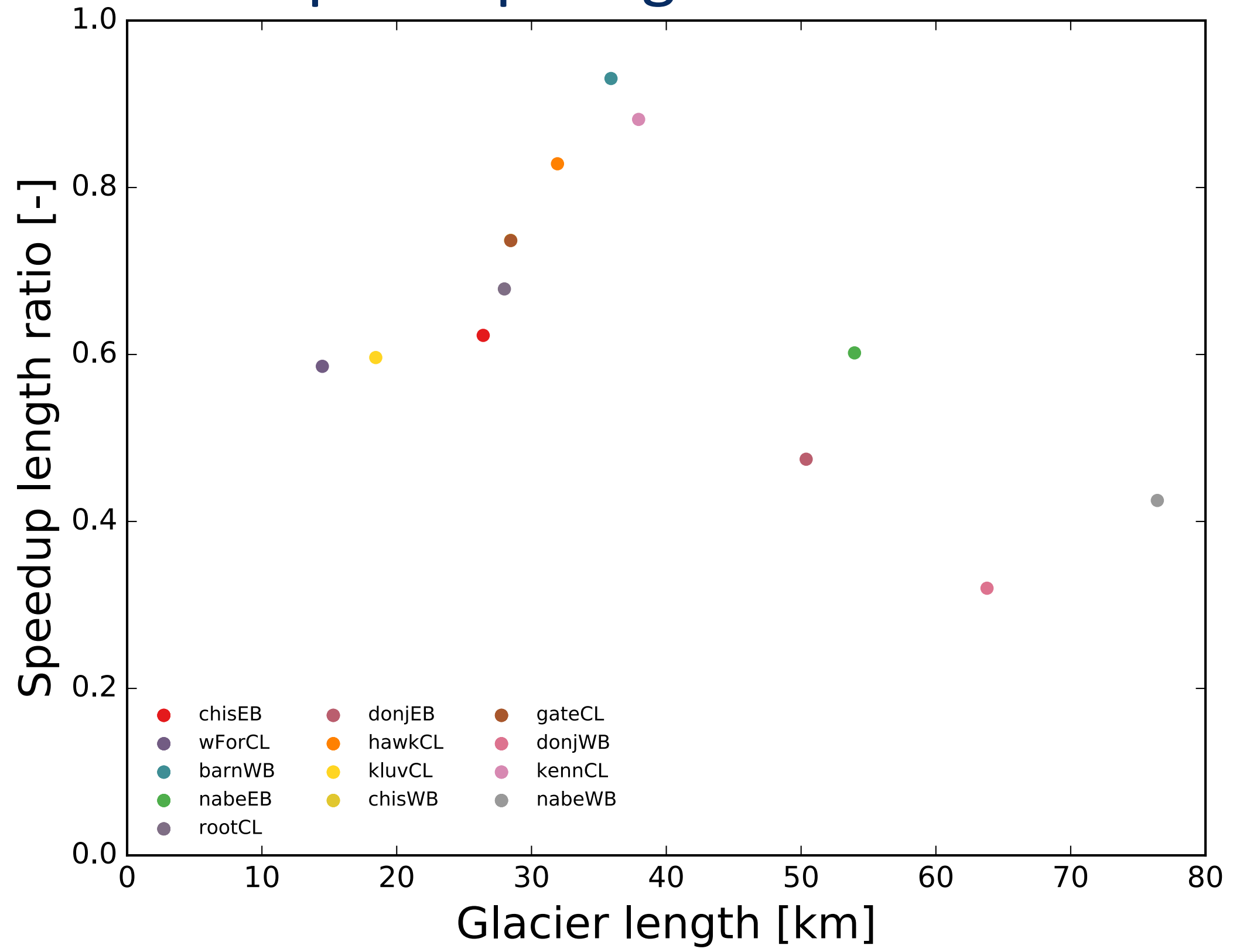




\section{Speedup profiles}

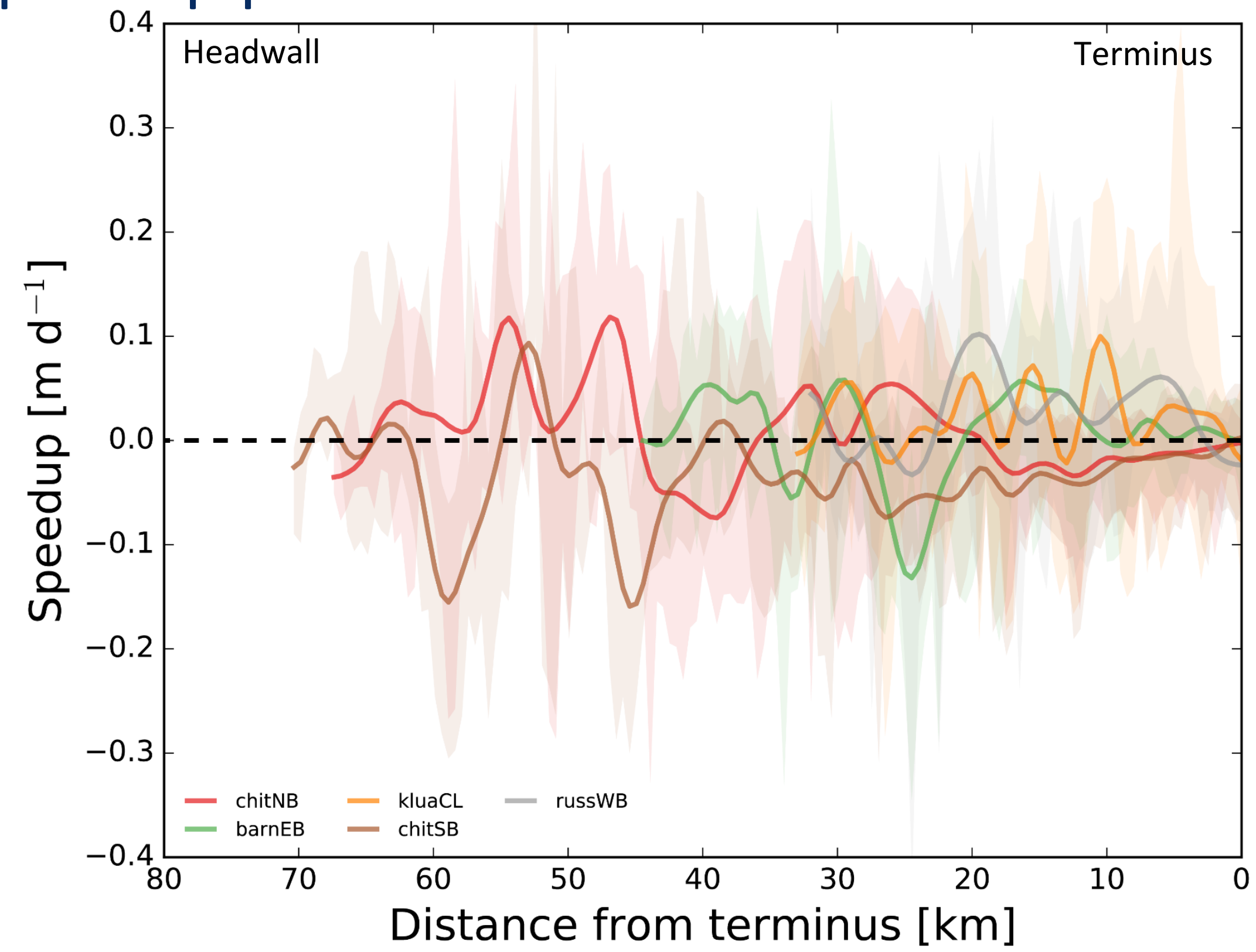




\section{Elevation distribution}

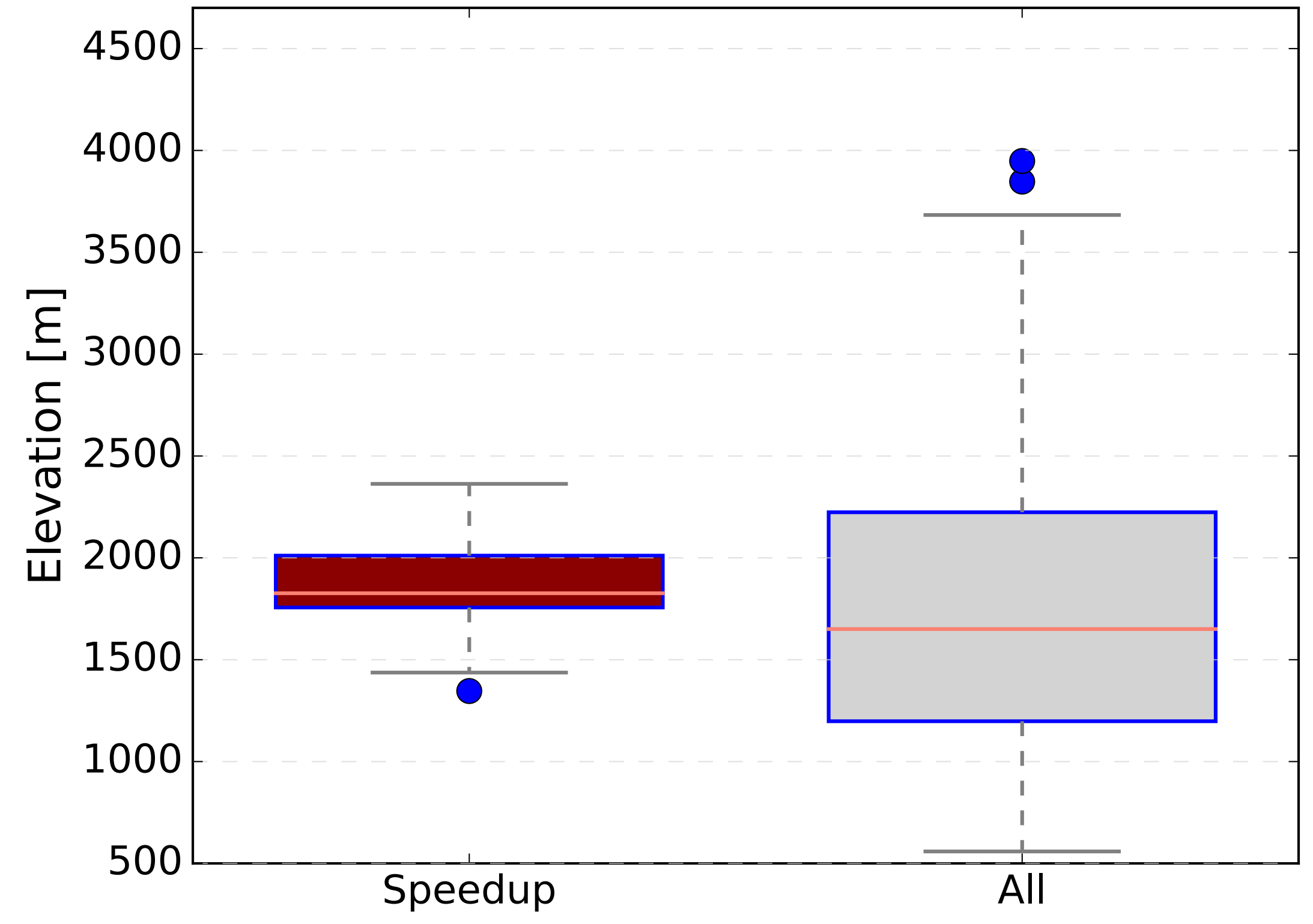




\section{Distance distribution}

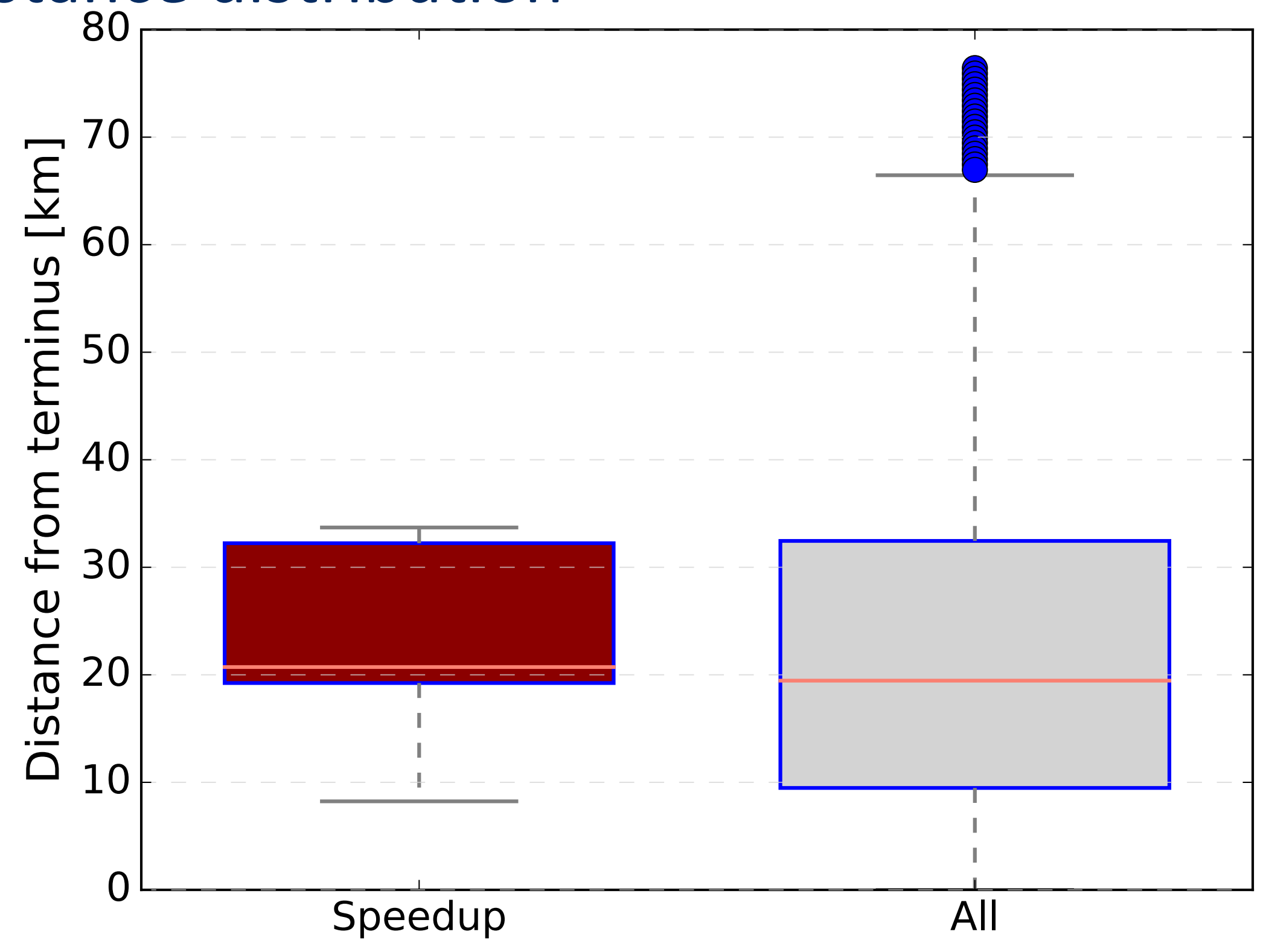


Glacier representation

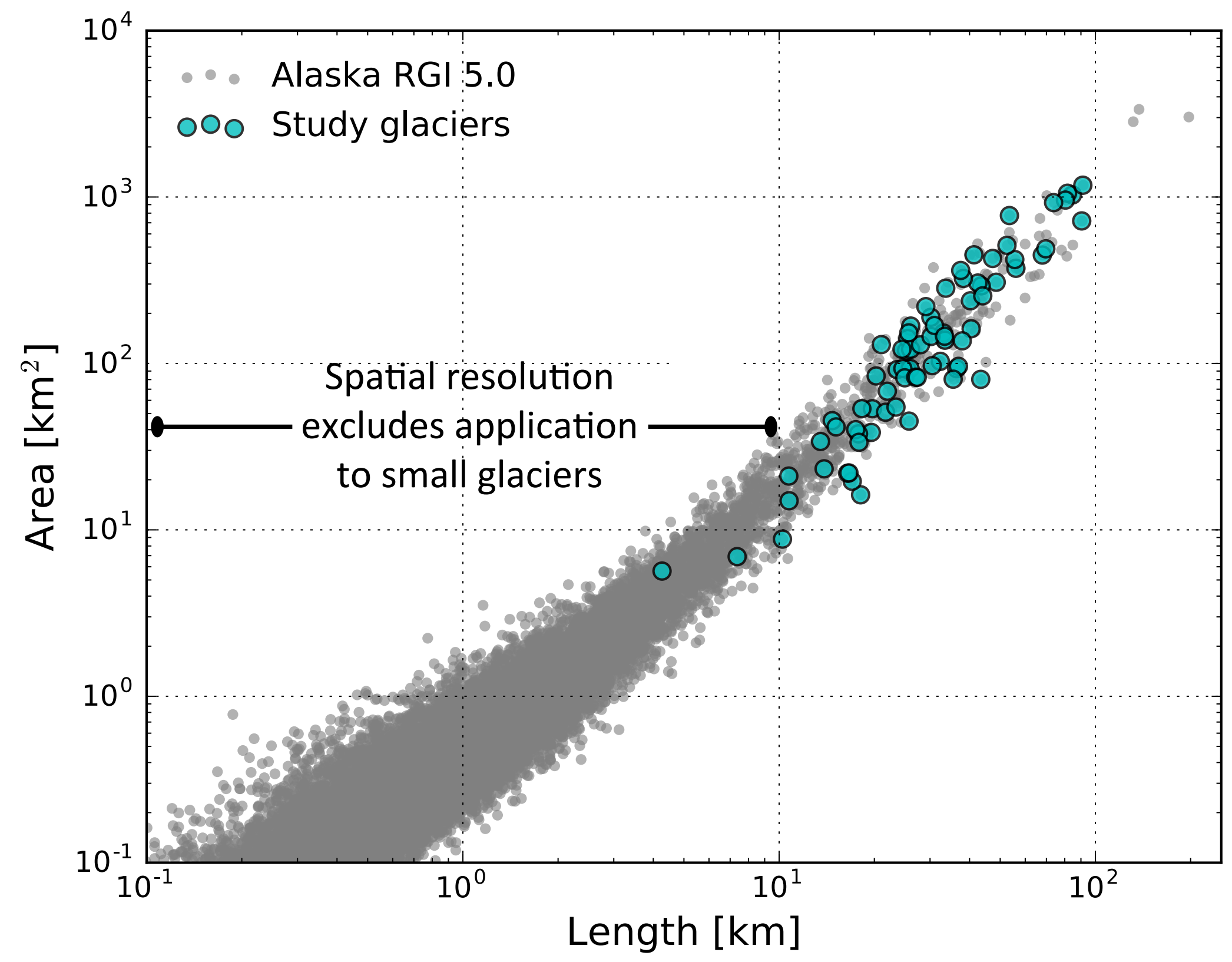




\section{Elevation distribution}

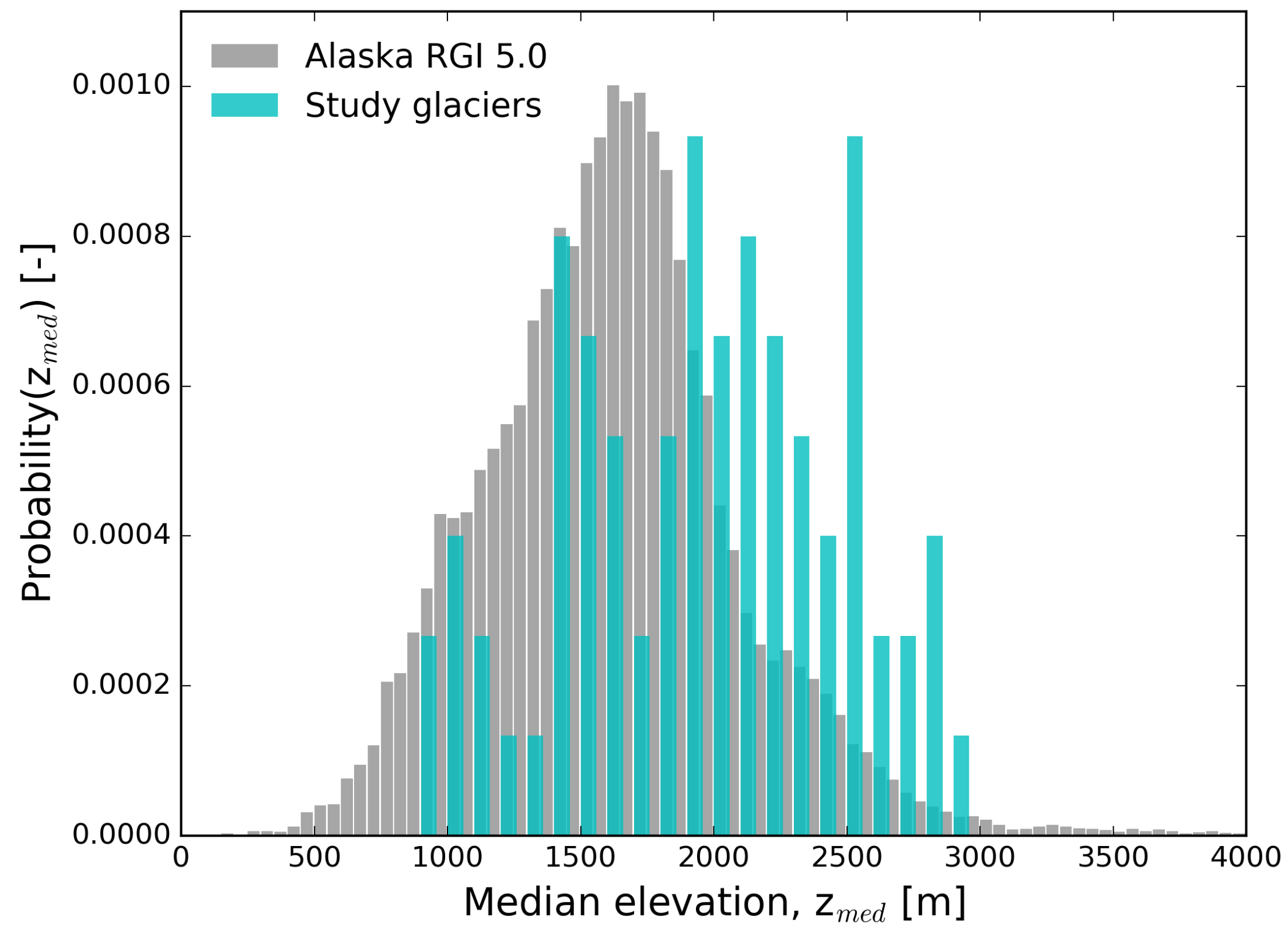




\section{Temporal coverage}

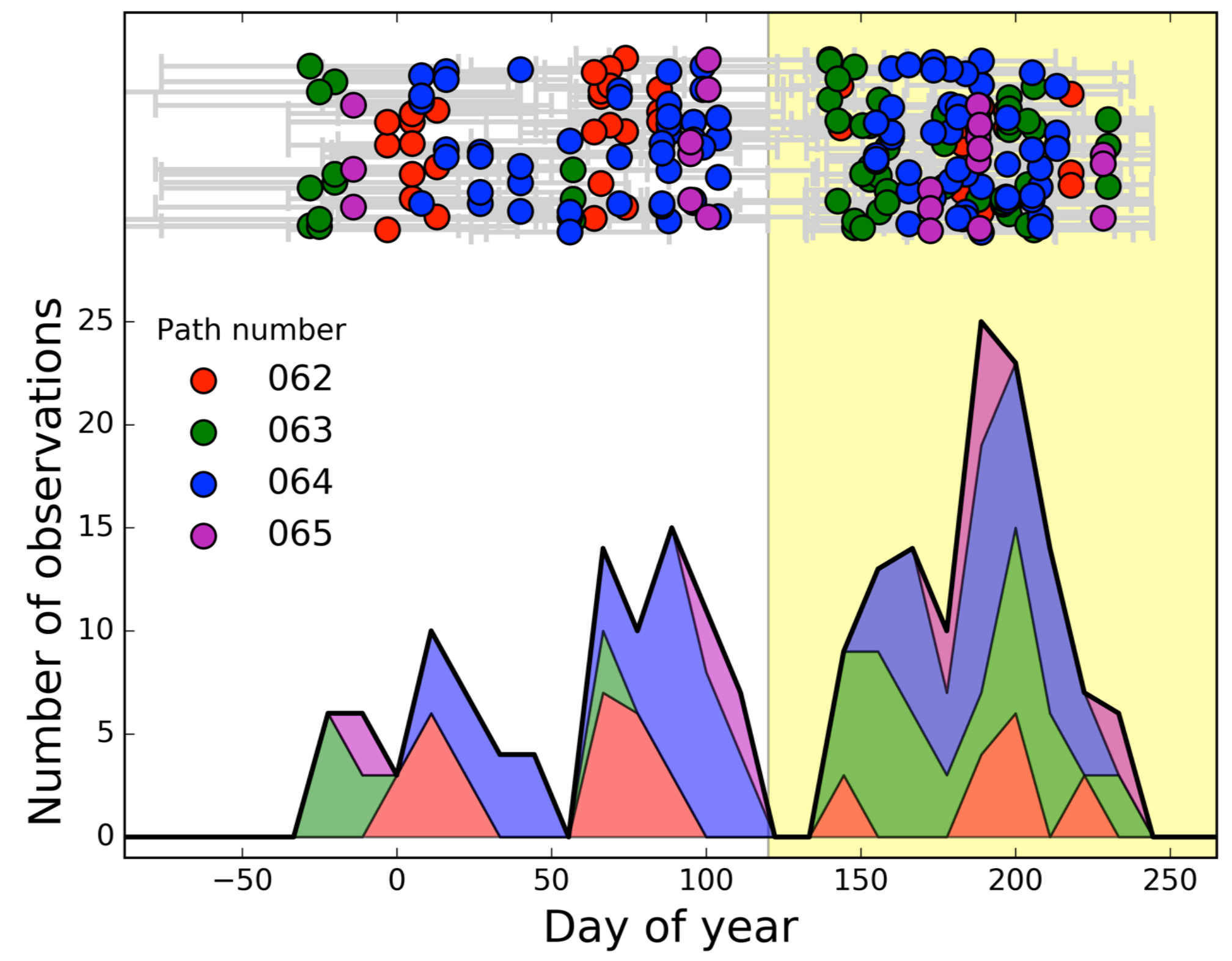




\section{Temporal resolution}

\section{- Majority $\leq 48$ days $\cdot$ Maximum $=160$ days}

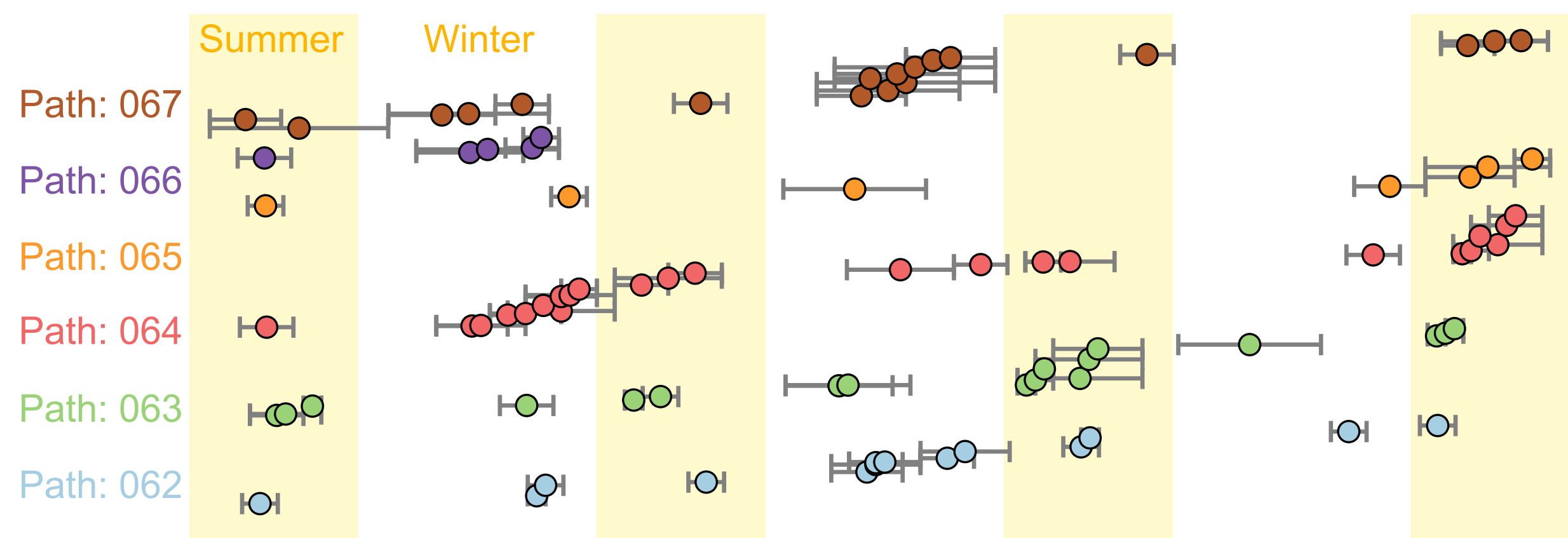

16 days

160 days

2013.5

2014.0

2014.5

2015.0

2015.5

2016.0 


\section{Temporal resolution}

Path: 068, Row: 017

Path: 067, Row: 017

Path: 066, Row: 017

Path: 065, Row: 017

Path: 064, Row: 017

Path: 063, Row: 017

Path: 062, Row: 017
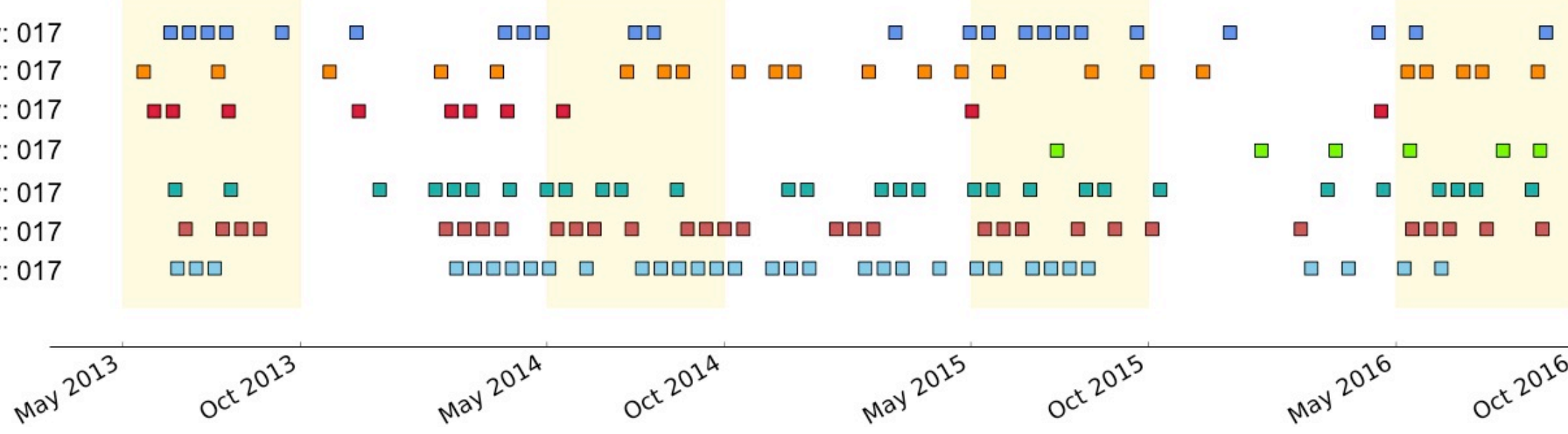

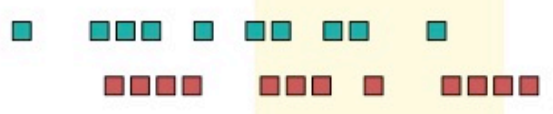

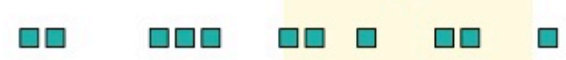

$\square \quad \square$

ㅁ $\square \square$

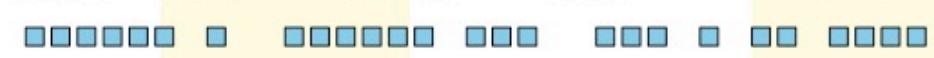
ㅁ

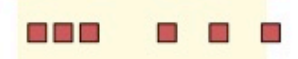

$\square \square \square \square$

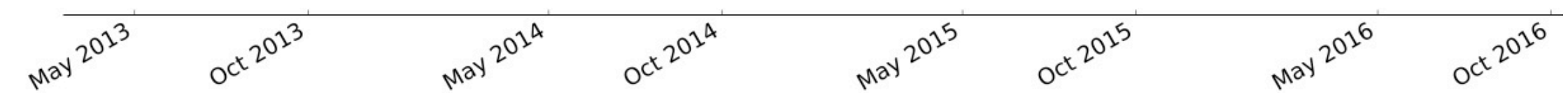

